\title{
Agulhas leakage into the Atlantic estimated with subsurface floats and surface drifters
}

\author{
Philip L. Richardson \\ Woods Hole Oceanographic Institution \\ Physical Oceanography Department, MS \#21 \\ 360 Woods Hole Road \\ Woods Hole, MA 02543 USA \\ And \\ Woods Hole Research Center \\ Woods Hole, MA 02543 \\ Telephone: 5082892546 \\ E-mail: prichardson@,whoi.edu
}

December 2, 2006 


\begin{abstract}
Surface drifters and subsurface floats drifting at depths near $800 \mathrm{~m}$ were used to study the pathways of warm salty Indian Ocean water leaking into the South Atlantic that is a component of the upper limb of the Atlantic meridional overturning circulation. Four drifters and 5 floats drifted from the Agulhas Current directly into the Benguela Current. Others looped for various amounts of time in Agulhas rings and cyclones, which translated westward into the Atlantic contributing a large part of Indian Ocean leakage. Agulhas rings translated into the Benguela Current where they slowly decayed. Some large blob-like Agulhas rings with irregular shapes were found in the southeastern Cape Basin. Drifter trajectories suggest these rings become more circular with time eventually evolving into the circular rings observed west of the Walvis Ridge. Agulhas cyclones, which form on the north side of the Agulhas south of Africa, translated southwestward (to $6^{\circ} \mathrm{E}$ ) and contributed water to the southern Cape Basin. A new discovery is a westward extension from the mean Agulhas retroflection measured by westward drifting floats near $41^{\circ} \mathrm{S}$ out to at least $5^{\circ} \mathrm{W}$ with some floats as far west as $25^{\circ} \mathrm{W}$. The Agulhas extension appears to split the South Atlantic Current into two branches and to transport Agulhas water westward where it is mixed and blended with eastward-flowing water from the western Atlantic. The blended mixture flows northeastward in the northern branch of the South Atlantic Current and into the Benguela Current. Agulhas leakage transport was estimated from drifters and floats to be at least $15 \mathrm{~Sv}$ in the upper 1,000 m, which is equivalent to the transport of the upper layer meridional overturning circulation. It is suggested that the major component of the upper layer overturning circulation in the Atlantic is Agulhas leakage.
\end{abstract}




\section{Introduction}

Interocean exchange of heat and salt around South Africa is thought to be key in maintaining the global overturning circulation of the ocean (Gordon et al., 1992; Lutjeharms, 1996; de Ruijter et al., 1999; Sloyan and Rintoul, 2001). Indian Ocean leakage into the South Atlantic takes place near the Agulhas Current retroflection where large Agulhas rings ( $400 \mathrm{~km}$ overall diameter) pinch off and translate into the Atlantic. Agulhas rings and other Agulhas eddies and current filaments merge with South Atlantic Current water in the Benguela Current, forming the source of the $\sim 15 \times 10^{6} \mathrm{~m}^{3} / \mathrm{s}$ warm upper layer water that flows northward through the Atlantic in compensation for the colder southward flowing North Atlantic Deep Water. Indian Ocean leakage water tends to be warmer and saltier than South Atlantic water of Drake Passage origin and therefore contributes to larger northward heat and salt fluxes (Gordon et al., 1992; Sloyan and Rintoul, 2001; Schmid et al., 2000). Variations of the leakage inferred from sea floor sediment cores and climate variations over the last 550,000 years suggest an enhanced leakage during present and past interglacials and a much reduced leakage during glacial intervals (Peeters et al., 2004). Agulhas leakage appears to play a crucial role in glacial terminations, the timing of interhemispheric climate change and the resulting resumption of the Atlantic meridional overturning circulation (MOC) (Peeters et al., 2004).

In order to correctly model the leakage and understand its effect on the overturning circulation and climate variations, the amounts and pathways of the present leakage need to be accurately measured and described. Mechanisms responsible for the leakage need to be understood and simulated realistically. However, the complexity of currents around southern Africa and the intense eddies in the vicinity of the Agulhas retroflection make it very difficult to measure the mean circulation patterns and interocean fluxes. At present we do not know accurately how much Agulhas leakage there is, what its variability is, and what percentage of leakage feeds into the upper limb of the MOC.

The purpose of this study is to use surface drifter and subsurface float trajectories to determine the amounts and pathways of the Indian Ocean leakage of surface and intermediate water $(\sim 800$ $\mathrm{m}$ ) and to investigate the physical mechanisms responsible for it. Leakage was investigated by studying individual trajectories that entered the Benguela Current from the Agulhas, including 
those in Agulhas rings and Agulhas cyclones, as well as overall patterns of trajectories. Physical characteristics of rings and cyclones were investigated in order to estimate their contribution to leakage. Finally, drifter and float velocities were used to map the mean flow field at high resolution $\left(1^{\circ} \times 1^{\circ}\right)$ in an attempt to reveal leakage pathways.

Acoustic float data in the region of interest have been previously discussed by Boebel et al. (2003), Lutjeharms et al. (2003), Richardson and Garzoli (2003), and Schmid et al. (2003). This present work builds on those studies by combining all available acoustic float trajectories, nonacoustic float displacements, and surface drifter trajectories to further examine surface and subsurface velocity characteristics of the flow field of the southeastern Atlantic where Indian Ocean leakage begins its northward path toward the equator. The intermediate-level mean flow field in the area of southern Africa has been mapped at fairly coarse $\left(\sim 3^{\circ}\right)$ resolution using acoustic floats (Boebel et al., 2003), non-acoustic floats (Davis, 2005), and a combination of acoustic and non-acoustic floats (Núñez-Riboni et al., 2005), but these maps tend to blur smaller scale features $\left(<3^{\circ}\right)$. The present study uses a higher resolution map $\left(\sim 1^{\circ}\right)$ in order to try and resolve the smaller features of the circulation in the vicinity of the Agulhas retroflection.

\section{Scientific Background}

The upper limb of the Atlantic MOC originates in the southeastern Atlantic where South Atlantic Current (SAC) water merges with Indian Ocean leakage in the Benguela Current (Reid, 1989; Peterson and Stramma, 1991; Stramma and England, 1999; de Ruijter et al., 1999). The two main sources of the upper layer MOC are Agulhas leakage and Drake Passage water that flows northward via the Falklands (Malvinas) Current and SAC. The Benguela Current flows northward as the eastern part of the subtropical gyre of the South Atlantic and then westward over the midAtlantic Ridge as the Benguela extension, which includes both the MOC and the return flow of the subtropical gyre. Upon reaching the western boundary the Benguela extension divides with (roughly) half flowing southward in the Brazil Current closing the gyre in the west and half flowing northward as the North Brazil Undercurrent and then North Brazil Current.

Accurate knowledge of the circulation patterns in the southeastern Atlantic and of the amounts of water from different sources in the Benguela Current has remained lacking because of the complexities of the ocean circulation and the sparse amount of suitable direct measurements. Complexities include the partially interconnected South Atlantic and Indian Ocean gyres and the 
formation of numerous energetic Agulhas rings and cyclones in the southeastern Atlantic. Good reviews of what is known have been published by de Ruijter et al. (1999) and Gordon (2001). Estimates of Agulhas leakage using geostrophic sections range from around 3-15 Sv (1 Sv $=10^{6}$ $\mathrm{m}^{3} / \mathrm{s}$ ), and estimates of leakage due to Agulhas rings range from around 3-9 Sv based on the formation of 6 rings per year each with a transport of 0.5 to $1.5 \mathrm{~Sv}$ (de Ruijter et al., 1999; Gordon, 2001). Estimates of the amount of intermediate water entering the Benguela Current from the Agulhas range from near zero (Rintoul, 1991) to around 50\% (Gordon et al., 1992).

Low salinity Antarctic Intermediate Water (AAIW) is one of the most prominent features of the Atlantic and can be clearly traced from the South Atlantic across the equator and into the Gulf Stream system. AAIW enters the subtropical gyre of the South Atlantic near its southwestern corner in the Brazil-Falklands confluence zone and also along the southern edge of the SAC (McCartney, 1977; Tsuchiya et al., 1994; Boebel et al., 1999a). Some SAC water enters the Benguela Current and some merges with the Agulhas Return Current and continues eastward past Africa. Part of this eastward flow loops into the subtropical gyre of the Indian Ocean and part loops into the Pacific Ocean and subsequently enters the Indian Ocean through the Indonesian Seas. Because the subtropical gyres of the Atlantic, Indian and Pacific are partially connected it is problematic to use water properties to clearly identify sources of the Benguela Current and to trace source waters downstream especially into the complicated eddy-rich Cape Basin.

Gordon et al. (1992) suggest that approximately $65 \%$ of the Benguela Current thermocline and as much as $50 \%$ of the intermediate water is derived from the Indian Ocean. In their scheme, the main supply of upper layer water flowing north across the equator is drawn from AAIW. Lower thermocline and intermediate leakage water passes to lower latitudes of the South Atlantic where significant amounts of intermediate water is transferred into the thermocline. Of $15 \mathrm{~Sv}$ of Agulhas leakage (above $1500 \mathrm{~m}$ ) 9 Sv continues northward in the MOC. Sloyan and Rintoul (2001) concluded that the Atlantic MOC is closed by cold fresh intermediate water that is modified to warm, salty varieties by air sea fluxes and interior mixing in the Atlantic and southwestern Indian Ocean. They suggest that the lower thermocline and intermediate water $\left(\mathrm{T}<10^{\circ} \mathrm{C}\right)$ in the Benguela Current comes from the SAC and Agulhas Current in equal amounts and that of $14 \mathrm{~Sv}$ flowing northward in the MOC, $10 \mathrm{~Sv}$ is derived from Agulhas leakage. Unresolved issues are the relative amounts at different depths of Indian Ocean water and Drake Passage water that flow northward in the MOC as opposed to being recycled around the western side of the Atlantic subtropical gyre and back into the SAC. A study using floats found that around a third of the 
intermediate water in the Benguela extension flows northward in the MOC along the western boundary and two-thirds flows southward in the Brazil Current (Boebel et al., 1999b; see also Schmid et al., 2000). This suggests that around $2 / 3$ of the upper $500 \mathrm{~m}$ of water in the Benguela extension continues northward in the MOC.

Agulhas Current leakage is dominated by extremely energetic eddies. Ship and satellite data have revealed the presence of numerous large (300-500 km diameter) rings of the Agulhas Current embedded in the Benguela Current. The rings form as the western part of the Agulhas retroflection pinches off from the main current (Lutjeharms and Van Ballegooyen, 1988). Approximately 5-6 rings form per year, and they have been tracked long distances across the Atlantic using satellite altimetry (Gordon and Haxby, 1990; Byrne et al., 1996; Goni et al., 1997; Schouten et al., 2000). Many rings have been measured at sea as described by Dumcombe Rae (1991), Lutjeharms (1996), Arhan et al. (1999), de Ruijter et al. (1999), Garzoli et al. (1999), and McDonagh et al. (1999). Agulhas rings are among the most energetic eddies in the world (Olson and Evans, 1986).

In order to directly measure the transport of the Benguela Current and its water mass constituents including leakage, the BEST program instrumented a section across the Benguela at $30^{\circ} \mathrm{S}$ from the Walvis Ridge $\left(3^{\circ} \mathrm{E}\right)$ to the coast of Africa. The mean northward transport of the Benguela was found to be $13 \mathrm{~Sv}$ in the upper 1,000 m with 50\% chiefly South Atlantic water, 25\% Agulhas water, and 25\% a blend of Agulhas and tropical Atlantic waters (Garzoli and Gordon, 1996). The results suggest that the Benguela Current has a stationary part located between the African Coast and $8^{\circ} \mathrm{E}$ and a transient component located between $8^{\circ} \mathrm{E}$ and the Walvis Ridge at $3^{\circ} \mathrm{E}$ composed mostly of Agulhas rings (Garzoli et al., 1997; Goni et al., 1997; Duncombe Rae et al., 1996). The results of BEST indicated a relatively small Benguela transport and a small Agulhas leakage transport $\sim 4 \mathrm{~Sv}$, which featured prominently in a review of the MOC by Schmitz (1995). Other reports of Benguela Current transport range from around $15 \mathrm{~Sv}$ to $25 \mathrm{~Sv}$ (Stramma and Peterson, 1989; Gordon et al., 1992; Sloyan and Rintoul, 2001). Differences of the observed Benguela transport and leakage are due to real fluctuations of the currents, Agulhas rings which are sometimes observed and sometimes not, different assumptions about a level of no motion, and different locations and end points of sections. In order to measure the whole Benguela transport including leakage, sections must include the whole ring corridor and all of the intermediate water contribution, which is offset to the west of the mean near surface Benguela Current. Some of this was missed by the BEST line. 
During 1997-1999, the KAPEX program seeded acoustic RAFOS floats in the intermediate water (around $750 \mathrm{~m}$ ) to measure the circulation in the vicinity of southern Africa including the Agulhas Current, the SAC component entering the Benguela, and the Benguela Current (Boebel et al., 1998). Overall objectives were to directly measure with floats the interocean exchange of water from the Agulhas into the South Atlantic and the advection of AAIW and its various mixing constituents in the South Atlantic. An important result was the observation of numerous cyclonic eddies in the Agulhas and in the southeastern Cape Basin (Lutjeharms et al., 2003; Boebel et al., 2003). Some of them translated southwestward into the South Atlantic and appeared to trigger the pinching off of Agulhas rings (Lutjeharms et al., 2003). The combined float trajectories reveal that the Cape Basin off Cape Town is virtually filled with Agulhas rings and cyclonic eddies, which interact intensely with each other, change shape, bifurcate, and merge (Fig. 1) (Boebel et al., 2003). These energetic eddies dominate the velocity field in the source region of the Benguela Current; they stir the various source waters and advect some of the blended product (trapped in the rings) westward over the Walvis Ridge. The earlier concept of a sluggish Benguela Current populated by a few isolated rings is no longer tenable except perhaps downstream, near and west of the Walvis Ridge. Agulhas leakage in the intermediate level (650$1250 \mathrm{~m}$ ) was estimated from a map of float velocities to be roughly $9 \mathrm{~Sv}$ (Boebel et al., 2003). The float data were also used to calculate the mean velocity of the Benguela extension downstream of the Cape Basin and were combined with geostrophic velocity profiles to calculate the transport of the Benguela extension over the mid-Atlantic Ridge (17-35 $\mathrm{S})$. The transport of the extension was around $30 \mathrm{~Sv}$ (including rings), with $15 \mathrm{~Sv}$ in the $0-500 \mathrm{~m}$ layer and $15 \mathrm{~Sv}$ in the 500-1000 m layer (Richardson and Garzoli, 2003).

Recently, two global ocean general circulation models were used with Lagrangian tracking of water parcels in the upper limb of the MOC to provide a new perspective on sources and pathways. Speich et al. (2001), using ORCA, found that 13.9 Sv of Agulhas leakage is joined by 2.3 Sv of Drake Passage water flowing through the Atlantic to comprise $16.2 \mathrm{~Sv}$ in the upper layer of the MOC (at $20^{\circ} \mathrm{N}$ ). The 13.9 Sv leakage includes 5.3 Sv from the Pacific that passes through the Indonesian Seas, 4.2 Sv of Drake Passage water that enters into the Indian Ocean, 3.1 $\mathrm{Sv}$ from the Pacific south of Australia and 1.3 Sv derived from the North Atlantic. Donners and Drijfhout (2004), using OCCAM, traced 16.2 Sv of MOC water back from the Atlantic equator and identified 15.2 Sv as being Agulhas leakage plus 1.0 Sv of Drake Passage water passing through the Atlantic. Of the total $17 \mathrm{~Sv}$ of leakage in the upper 1,000 m, $15 \mathrm{~Sv}$ continue 
northward in the MOC, and $2 \mathrm{~Sv}$ are recycled around the gyre. Approximately $2 / 3$ of the leakage is located in the upper $500 \mathrm{~m}$ and 1/3 between 500-1,000 $\mathrm{m}$. These two studies indicate that almost all of the Agulhas leakage in the upper 1,000 m continues north in the MOC and that this leakage is joined by relatively small amounts of Drake Passage water entering through the Atlantic (1-2 Sv). This is in contrast to Gordon et al. (1992) who found $9 \mathrm{~Sv}$ of the $15 \mathrm{~Sv}$ leakage to continue northward in the MOC and Sloyan and Rintoul (2001) who found $10 \mathrm{~Sv}$ of $14 \mathrm{~Sv}$ leakage to continue northward.

\section{Data and Methods}

\subsection{Drifters}

All available drifting buoy data for the relevant region were acquired from the Global Drifting Buoy Data Assembly Center at the NOAA Atlantic Oceanographic and Meteorological Laboratory in Miami Florida. The drifters are similar to the WOCE-TOGA Lagrangian drifter described by Sybrandy and Niiler (1991). Drogues were attached below the surface float and centered at a depth of $15 \mathrm{~m}$. Overall, 321 surface drifter trajectories were obtained for the region of interest and consist of 4 values per day of position and velocity (Fig. 2). The data set comprise 238 drifter years of data from the years 1994-2004.

Near surface geostrophic velocity was estimated by removing the wind-correlated part of the drifter velocity, which contains contributions of Ekman velocity, Stokes drift, and errors such as drogue slip. NCEP reanalysis winds at a height of $10 \mathrm{~m}$ above sea level, which had been interpolated to drifter positions, were provided by P. Niiler and N. Maximemko (personal communication). The east and north drifter velocity components were regressed (multiple linear) against the east and north wind velocity components in two areas of nearly constant mean drifter velocity, one in the Benguela area $\left(25-30^{\circ} \mathrm{S}, 2-15^{\circ} \mathrm{W}\right)$ and the other in the SAC area $\left(35-40^{\circ} \mathrm{S}\right.$, $\left.5^{\circ} \mathrm{W}-10^{\circ} \mathrm{E}\right)$. The regression coefficients relating current and wind speed were similar in the two areas, so the data (130,000 observations) were grouped to obtain representative overall coefficients (after subtracting the mean drifter velocity at zero wind velocity in each area). The wind-driven part of drifter velocity (and standard error) was estimated as being $0.968 \%$ ( \pm $0.029 \%)$ of the wind speed at $37.2^{\circ}\left( \pm 1.7^{\circ}\right)$ to the left of the wind direction. Drifter velocities were corrected using this relationship. 


\subsection{Floats}

All available subsurface float data at intermediate water depths (Fig. 3) were acquired from the WOCE Subsurface Float Data Assembly Center (http://wfdac.whoi.edu). Two different types of floats were available — acoustic and non-acoustic (see Gould, 2005; Núñez-Riboni et al., 2005). The first type, RAFOS (Ranging And Fixing Of Sound) floats, were launched as part of KAPEX (Boebel et al., 1998; Richardson et al., 2003) and were tracked acoustically, which provided position and velocity at daily intervals (Rossby et al., 1986). A subset of the KAPEX floats launched in the Agulhas Current were constructed to be isopycnal so they could follow the vertical as well as horizontal motions of water parcels (Lutjeharms et al., 2003). The rest of the KAPEX floats launched in the SAC (Boebel et al., 2003) and Benguela Currrent (Richardson and Garzoli, 2003) were quasi-isobaric and tend to drift at nearly constant depths. In these regions vertical motions are smaller than in the Agulhas, so it is less important that the floats are isopycnal. However, it should be cautioned that these floats are only quasi-Lagrangian in the presence of vertical water motions.

KAPEX deployments were made in the SAC during March-April 1997 and in the Benguela Current during September 1997. In both areas floats were launched over a wide geographic area and were centered at a depth near $800 \mathrm{~m}$. Two main float deployments were made in the Agulhas Current (Lutjeharms et al., 2003). The first was along a line extending off Port Elizabeth near $26^{\circ} \mathrm{E} 35^{\circ} \mathrm{S}$ on 3 December 1997 . The second was along two lines separated by $100 \mathrm{~km}$ off Durban near $31^{\circ} \mathrm{E} 31^{\circ} \mathrm{S}$ on 13 and 15 June 1998. The Agulhas floats were ballasted for one of two density surfaces, 26.8 and 27.2, and typically equilibrated at depths of 300-1100 m. Most of the floats were launched on the inshore part of the Agulhas or near its center; this becomes important in interpreting the resulting trajectories because most of these floats were caught in cyclonic eddies. The KAPEX floats were tracked from March 1997 to September 1999 and provided 104 float years of data Fig. 3).

The second type of floats are non-acoustic ALACE (Autonomous Lagrangian Circulation Explorer) floats (Davis et al., 1992; Davis, 2005). These are quasi-isobaric and periodically rise to the surface to be positioned by satellite and then return to their original depth to continue drifting. Typical submerged drift times are 10 and 25 days. Because of periodic breaks in the subsurface drift of these floats, a series of subsurface displacements is not a trajectory of a water parcel. Subsurface displacements and velocities of ALACE floats were interpolated to daily values in 
order to combine them with the daily RAFOS data. Around 86 float years of ALACE-type float displacements were acquired for the region of interest, most measured during the years 1996 to 2000 .

\subsection{Eddy characteristics}

Looping drifter and float trjectories were studied to identify discrete eddies and to estimate their characteristics. The number of loops was estimated visually from the trajectories and used to estimate the period of rotation (T) by dividing the days tracked by the number of loops. The characteristic swirl speed (Vs) was estimated as being equal to the root mean square velocity about the mean velocity ( $\mathrm{U}$ in the east direction and $\mathrm{V}$ in the north direction) averaged over each looper series. The mean diameter (D) was estimated from the mean looping period (T) and mean swirl speed (Vs) with the relation $\mathrm{D}=\mathrm{VsT} / \pi$. Maximum swirl speed, maximum diameter, and minimum period of rotation averaged over a loop were also estimated for each looper trajectory and velocity time series. Since the period of rotation and swirl speed vary with radius, these characteristics estimated from a trajectory are representative of the radius sampled rather than for a whole eddy. This should be kept in mind when comparing characteristics of different eddies.

Rossby number (Ro) was estimated for some eddies by $\operatorname{Ro}=\zeta / \mathrm{f}$, where $\zeta=2 \omega$ is the relative vorticity of an eddy (assuming solid body rotation), $\omega$ is the angular velocity of the eddy measured by a drifter or float, and $\mathrm{f}$ is the Coriolis parameter, $\mathrm{f}=2 \Omega \sin \theta$. If a drifter or float was located outside the (approximately) solid body rotation core region of an eddy, then the calculated Rossby number could under estimate the solid body rotation rate. The Rossby number of an eddy can be expressed in terms of its period of rotation ( $T$ in days) as Ro $=1 /(T \sin \theta)$, where $T$ was estimated from the looping drifters and floats.

\subsection{Velocity maps}

In order to map velocity fields, surface drifter velocities and float velocities in the depth range of intermediate water, $500-1100 \mathrm{~m}$, were grouped into $1^{\circ} \times 1^{\circ}$ geographical bins for the two levels, and average velocity, variance about the mean velocity, standard error and eddy kinetic energy were calculated. The average depth of the floats used in mapping was $810 \mathrm{~m}$, and the standard deviation about the mean was $120 \mathrm{~m}$. Mean velocity was calculated as the sum of all u velocity components in the $\mathrm{x}$ direction in a bin divided by the number of observations, similarly for $\mathrm{v}$ 
velocity in the y direction. Eddy kinetic energy (EKE) was calculated by averaging the $u$ and $v$ velocity variances about the mean velocities in each bin. The number of degrees of freedom $\mathrm{N} / \tau$ was estimated by summing the number of days of daily drifter or float velocity observations within a bin $(\mathrm{N})$. $\mathrm{N}$ was divided by the integral time scale ( $\tau \sim 2$ days for drifters, $\tau \sim 4$ days for floats) of the Lagrangian autocorrelation function, which was estimated using 41 representative 50-day series of drifter velocities and 28 representative 50-day series of RAFOS float velocities from the Cape Basin region. In practice, $\mathrm{N} / \tau$ was estimated by summing the number of two-day intervals for which each drifter was within a bin and the number of four-day intervals for which each float was within a bin. The number of degrees of freedom was used to eliminate vectors in bins containing sparse data $(\mathrm{N} / \tau<6)$ and to estimate standard errors. Standard error of the mean velocity was estimated using $(2 \mathrm{~S} \tau / \mathrm{N})^{1 / 2}$, where $\mathrm{S}$ is the variance of velocity about the mean velocity. To create maps, the $1^{\circ} \times 1^{\circ}$ velocity and EKE values which were calculated using bins bounded by even degrees were lightly smoothed and gaps were filled by interpolating values to even degrees using "triangulate" in the Generic Mapping Tools, GMT (Wessel and Smith, 1998).

\section{Direct observations of Agulhas leakage}

Drifter and float trajectories were inspected for evidence of direct leakage from the Agulhas Current into the Benguela Current and also for eastward return flow of Agulhas water south of the Agulhas. Some of the trajectories were extremely convoluted in the vicinity of the retroflection and some instruments died before going very far northwest or east. It was not always easy to subdivide trajectories into northwestward and eastward ones. In practice, it was decided to consider all drifters and floats that drifted westward across $20^{\circ} \mathrm{E}$ that had either been launched upstream in the Agulhas or that had been clearly drifting in the Agulhas for a reasonable distance before reaching $20^{\circ} \mathrm{E}$. This longitude, $20^{\circ} \mathrm{E}$, lies near Cape Agulhas and the southern tip of the Agulhas Bank south of Africa and therefore represents the boundary between the Indian and Atlantic Oceans. Acceptable trajectories were required to be clearly heading northwestward well in the Benguela Current or eastward well south of the Agulhas.

Using the above definition there were 36 acceptable drifters and floats in the Agulhas of which 9 entered the Benguela Current and 27 returned eastward south of the Agulhas (Fig. 4). This suggests that around $25 \%$ of the Agulhas leaks into the Atlantic. Four of the 12 acceptable drifters $(33 \%)$ entered the Benguela. Two of eleven acceptable isopycnal RAFOS floats launched in the Agulhas (18\%) drifted into the Benguela, one near depths of 200-300 m, the other near $600 \mathrm{~m}$. Three of the 13 acceptable ALACE-type floats (23\%) at intermediated depths (near $800 \mathrm{~m}$ ) 
drifted into the Benguela. One additional ALACE float clearly in the Agulhas drifted far west of the retroflection near $41^{\circ} \mathrm{S}$, out to $5^{\circ} \mathrm{W}$ before turning back eastward again in the northern branch of the SAC. This float died before it reached the Benguela Current, but several other floats in the same region entered the Benguela, so this float might have done so too. This raises the possibility of a different and more indirect westward route for Agulhas water to enter the Benguela. Some potential biases of the different kinds of measurements are discussed in Appendix A and some details concerning RAFOS leakage floats in Appendix B.

The directly measured transport of the Agulhas in the upper $1,000 \mathrm{~m}$ (near $32^{\circ} \mathrm{S}$ ) from two sections is $63 \mathrm{~Sv}$ and $70 \mathrm{~Sv}$ (Beal and Bryden, 1999; Donohue and Firing, 2000). Combining the mean transport of these $(66.5 \mathrm{~Sv})$ with the $25 \%$ of floats and drifters that entered the Benguela from the Agulhas suggests a leakage transport of $15.3 \mathrm{~Sv}$. A better estimate of leakage transport is obtained by dividing the Agulhas into a near surface layer and a deeper layer and using the appropriate transport for each layer calculated from the velocity section shown by Beal and Bryden (1999). If we assume that the leakage of drifters is representative of the wind-forced Ekman layer in the upper $50 \mathrm{~m}$ of the Agulhas $(5.3 \mathrm{~Sv})$ and the combined leakage by RAFOS and ALACE floats (5 out of 24 floats) is representative of the 50-1,000 m layer of the Agulhas (61.2 $\mathrm{Sv}$ ), then the estimated leakage transport is $14.5 \mathrm{~Sv}$. As a measure of transport uncertainty, it is estimated that if one more float had entered the Benguela Current (from the Agulhas extension, for example) then the $14.5 \mathrm{~Sv}$ value would have increased by $1.9 \mathrm{~Sv}$. Another estimate is that if the drifter data were representative of the upper $100 \mathrm{~m}$, instead of $50 \mathrm{~m}$, then the estimated leakage would increase by around $1.5 \mathrm{~Sv}$. Thus, there is a fairly large uncertainty associated with these direct measurements of leakage.

The estimates of leakage using drifters and floats agree closely with recent results of a high resolution numerical modeling study of the region around southern Africa. Doglioli et al. (2006) used a Lagrangian particle-following technique to estimate that about 43,000 out of 176,000 simulated particles (24\%) released near $32^{\circ} \mathrm{S}$ in the Agulhas made the connection to the Atlantic Ocean giving a direct measure of leakage transport amounting to $14.5 \mathrm{~Sv}$.

Trajectories of drifters and floats that leaked into the Benguela Current were reviewed in order to search for trends. Two of the 4 Agulhas leakage drifters looped in anticyclones, which are interpreted to be Agulhas rings and which were translating generally northwestward. One of these drifters started looping just after crossing $20^{\circ} \mathrm{E}$ in what appeared to be a newly formed ring. 
The drifter stopped looping as the ring encountered the Schmitt-Ott Seamount (minimum depth of $304 \mathrm{~m}$ ), similar to what happened to a ring observed by Olson and Evans (1986). The two other drifters drifted rather uneventfully northwestward up the coast. This same trend is seen in another 8 drifter trajectories that crossed $20^{\circ} \mathrm{E}$ near the Agulhas and entered the Benguela Current; some were in rings, some others drifted uneventfully northwestward. Both RAFOS floats that leaked into the Benguela made some anticyclonic loops on their way northwestward in rings. Nothing obvious was seen in the ALACE trajectories, but their low temporal resolution prevents much inference about rapidly rotating eddies. In summary, the trajectories in the Benguela suggest that around half of the drifters and floats were entrained into rings for part of their drift in the Benguela, but these episodes did not appear to dominate the trajectories.

\section{Inflow to Benguela Current from the South Atlantic Current}

Most drifters in the vicinity of the SAC south of around $41^{\circ} \mathrm{S}$ continued eastward south of the Agulhas. Most drifters in the SAC north of around $41^{\circ} \mathrm{S}$ drifted northeastward into the Benguela Current and then started to turn westward between $30-35^{\circ} \mathrm{S}$. These partially merged with those leaking in from the Agulhas, although the leakage drifters tended to drift northwestward closer to the African coast (between $12-17^{\circ} \mathrm{E}$ near $30^{\circ} \mathrm{S}$ ) than most of those entering directly from the SAC. A broad swath of drifters going north crossed $30^{\circ} \mathrm{S}$ east of $10^{\circ} \mathrm{W}$ giving the impression of a wide eastern boundary current. Drifters tended to not go north of $20^{\circ} \mathrm{S}$ where they drifted due westward, some entering the Brazil Current and heading southwestward on the western side of the subtropical gyre. The implication from drifters is that no surface water flows northward to the equator. In reality, near surface water is subducted and has been traced northward to the equator below the surface layer. For example, Zhang et al. (2003; see also Snowden and Molinari, 2003) used drifters and hydrography to trace subducted water through the South Atlantic and into the northward flowing North Brazil Undercurrent (Schott et al. 2005).

Numerous ALACE trajectories drifted eastward in the SAC between latitudes of $35-50^{\circ} \mathrm{S}$ (see Fig. 3). Near $15^{\circ} \mathrm{W}$, just east of the mid-Atlantic Ridge, the ALACE trajectories appear to divide into two branches, one north of around $40^{\circ} \mathrm{S}$ and the other south of around $43^{\circ} \mathrm{S}$, leaving an area with very few trajectories centered near $41^{\circ} \mathrm{S}$ (between $5-15^{\circ} \mathrm{W}$ ). This is just west of where the Agulhas extension was observed with westward drifting floats as described below. Six ALACES in the SAC $\left(35-45^{\circ} \mathrm{S}\right)$ turned northward and entered the Benguela, 4 just west of Cape Town, and two others near $10^{\circ} \mathrm{W}$ and $3^{\circ} \mathrm{E}$ (at $35^{\circ} \mathrm{S}$ ). Two of these were entrained into Agulhas rings for 
long drifts (6 and 13 months). The 6 ALACES tended to merge in the Benguela with those entering from the Agulhas. Most of the ALACES in the southern branch of the SAC (south of $43^{\circ} \mathrm{S}$ ) continued eastward south of the Agulhas.

\section{Agulhas rings and cyclones}

Each drifter and float trajectory was visually examined for loops and cusps, which reveal the characteristic motion of a particle in an eddy — a swirl velocity around an eddy center plus its translation. Time series of velocity, temperature and pressure were checked to help estimate when a float entered and exited an eddy. An eddy was defined as two or more consecutive loops in the same direction (looper) within a trajectory. This definition attempts to identify discrete eddies (coherent vortices) with their approximately symmetrical rotational circulation and the volume of trapped fluid that translates with the eddy, and to discriminate them from other types of fluctuating ocean motions. Clockwise loopers were in cold core cyclones and counterclockwise loopers were in warm core anticyclones.

A summary of cyclonic and antiyclonic loopers measured by surface drifters is shown in Fig. 5, and loopers measured by floats in Fig. 6. A summary of the trajectories of anticyclones and cyclones drawn manually through drifter and float trajectories is shown in Figs. 7 and 8. Overall, there were 99 loopers, 47 cyclonic and 52 anticyclonic (Table 1). Sixty-eight eddies were tracked including 33 cyclones and 35 anticyclones (Table 2). The majority of anticyclones are interpreted to be Agulhas rings. Many cyclones in the southeastern Cape Basin are interpreted to be Agulhas cyclones. The longest tracked eddies were two rings observed with floats for 18 months and 19 months, both over distances of 2,000 km. The most loops in an eddy were 32 in a $30^{\circ} \mathrm{S}$ cyclone that was tracked with a drifter for 14 months and over a distance of almost $2,000 \mathrm{~km}$. These are records for the longest time and distance of a looping drifter. The smallest period of rotation in the Cape Basin was 3 days for some small $\sim 20 \mathrm{~km}$ loops in an Agulhas cyclone $(\mathrm{Ro}=0.5)$.

Ring circulation is not well resolved with the low temporal resolution ALACE displacements, so the three ALACE trajectories in rings appear jagged in Fig. 6. However, two RAFOS floats looped in two of the rings tracked by ALACE floats, confirming they were in rings. Fig. 6 includes two ALACE trajectories, one because it is longer than the corresponding RAFOS trajectory in the ring, and the other because it was the only one in the ring. No ALACE trajectory 
looks like it contains cyclonic loops, probably because the somewhat faster rotation rate of cyclones could not be resolved.

During KAPEX, 6 drifters and 8 RAFOS floats were launched on purpose in three rings that were surveyed by ship near $30^{\circ} \mathrm{S}$ at $31.1^{\circ} \mathrm{S} 9.0^{\circ} \mathrm{E}, 31.2^{\circ} \mathrm{S} 3.8^{\circ} \mathrm{W}$, and $29.8^{\circ} \mathrm{S} 6.1^{\circ} \mathrm{W}$ (Garzoli et al., 1999; Richardson and Garzoli, 2003). Thus, trajectories of 3 rings in Fig. 7 were of these seeded rings. Five other RAFOS floats were launched in a newly formed ring located near $37^{\circ} \mathrm{S} 16^{\circ} \mathrm{E}$ (Schmid et al., 2003). None of these were classified as a looper, although when taken together the float trajectories indicated that the ring translated northwestward. Aside from these specific deployments in rings, the eddy trajectories were obtained by drifters or floats entrained into eddies, plus a few launched in eddies by chance. When several drifters (or floats) were in an eddy, the longest trajectory is shown in Figs. 5 and 6 except where two (or more) trajectories overlap to provide a longer eddy trajectory.

\subsection{Anticyclones (Agulhas rings)}

Drifters and floats give a rather similar picture of anticyclones, which are interpreted to be Agulhas rings. Virtually all rings translated (generally) northwestward, some passing over the relatively shallow Walvis Ridge. Some drifters and floats stopped looping near the ridge, and others changed looping characteristics indicating a disruption of the normal ring circulation by the ridge. The pattern of ring trajectories observed here matches rings tracked altimetrically by Byrne et al. (1995), Goni et al. (1997), Schouten et al. (2000) and Boebel et al. (2003).

Two anticyclone trajectories differ from this picture (Fig. 8). One trajectory in the southwest was outside the ring corridor and went northeastward which suggests it was not a ring. Another trajectory was located in the Agulhas and went southwestward. This could have been an anticyclone translating southwestward embedded in the Agulhas, or alternatively could have been associated with the retroflection, which was advancing southwestward after an Agulhas cyclone cut southward across the Agulhas near $22^{\circ} \mathrm{E}$ causing a ring to pinch off from the previous retroflection (see Lutjeharms et al., 2003).

The mean velocity of the rings using the 5 longest loopers (all $>$ one year long) was $4.4 \mathrm{~cm} / \mathrm{s}$ (range $=3.2-5.9 \mathrm{~cm} / \mathrm{s}$ ) toward $287^{\circ}$. A comparison of drifter and float data where they overlap in the same rings at roughly the same diameter and time suggests that the surface swirl velocity of 
rings and their rotation rate is around 2-3 times larger than the intermediate depth $(\sim 800 \mathrm{~m})$ swirl velocity and rotation rate. Thus rings are clearly surface intensified.

The most energetic rings are located in the southeastern Cape Basin. Average drifter swirl speeds of 5 rings there generally fall within $40-60 \mathrm{~cm} / \mathrm{s}$ with a high of $86 \mathrm{~cm} / \mathrm{s}$ for the ring closest to Cape Town. Average drifter swirl speeds in rings decrease with distance from the Agulhas retroflection, from the large values given above down to around $40 \mathrm{~cm} / \mathrm{sec}$ at a distance of 1,000 $\mathrm{km}$ and to around $25 \mathrm{~cm} / \mathrm{s}$ at $2,500 \mathrm{~km}$. The estimated e-folding distance for the decay of swirl speed is around $1300 \mathrm{~km}$, well within the Cape Basin. At an average ring velocity of $4.4 \mathrm{~cm} / \mathrm{s}$ rings would have traveled $1300 \mathrm{~km}$ in around 340 days. This is consistent with the decay of dynamic height anomalies in rings determined from altimetry (Byrne et al., 1995; Schouten et al., 2000) and to the decrease of eddy kinetic energy along the ring paths. Typical average ring diameters are around $200 \mathrm{~km}$ and maximum diameters are $250 \mathrm{~km}$ for most of the rings with little or no trend with distance. Note that the overall diameter of rings (outer limits) is larger than the largest loops (Olson and Evans, 1986; Arhan et al., 1999; Garzoli et al., 1999). The average period of rotation of rings increases from around 10 days in the southeast $(\mathrm{Ro}=-0.16)$ to $20-40$ days in the northwest $(\mathrm{Ro}=-0.07)$.

Only one ring was measured with a float (at $560 \mathrm{~m}$ ) in the southeastern Cape Basin. Its average swirl speed was $34 \mathrm{~cm} / \mathrm{sec}$, which suggests that the surface swirl velocity of rings there is intensified by a factor of around 1.6 times. Older rings measured by floats have typical average swirl speeds around $10 \mathrm{~cm} / \mathrm{s}$ and typical maximum diameters are $200-250 \mathrm{~km}$.

Virtually all the KAPEX RAFOS floats that crossed over the Walvis Ridge did so associated with five rings and one cyclone. A possible explanation is that the ridge is less of a barrier to water swirling in rings than outside of them (Richardson and Garzoli, 2003). Rings have a persistent northwestward translation over the ridge and their rapid $\sim 15 \mathrm{~cm} / \mathrm{s}$ swirl velocity at $750 \mathrm{~m}$ partially traps water (Flierl, 1981) and advects it over the ridge. Another explanation is that ring translation, which is faster than the mean background flow, could have advected the floats over the ridge before they reached it in the slower mean background flow field. However, 5 ALACE floats crossed over the Walvis Ridge, only one of them in a ring. Although it is possible that these ALACE floats were influenced by their periodic surfacings, which could have helped advect the floats westward, the surface displacements are small and do not look as if they had a significant role in advecting the floats over the ridge. This is consistent with the low surface 
velocities observed there by drifters. Therefore, in contrast to RAFOS floats, the ALACE floats suggest that the Walvis Ridge is not a barrier to the background (non-ring) flow.

\subsection{Irregular Anticyclones}

In addition to the nearly-circular loopers in Agulhas rings west of the Walvis Ridge (Figs. 5 and 6), there are some anticyclonic drifter loops that are much more irregular in shape. For simplicity these less circular anticyclones will be called blobs. Blobs are inferred to have been shed from the retroflection and are therefore Agulhas rings, although their shape is not very circular or ringlike. An inspection of drifter trajectories indicates a wide variety of loop shapes extending from the almost perfectly circular loops in some rings west of the Walvis Ridge to more highly irregular loops in blobs, which tend to be located in the southeastern Cape Basin. A few anticyclonic blobs were located near the western edge of the mean Agulhas retroflection and could have been newly formed rings. Because of the irregular loops, trajectories in blobs were not included as loopers, except for a few of the more regular-shaped blobs. Anticyclonic blobs coincide with the locations of anticyclonic loopers in the southeastern Cape Basin (Fig. 5). Drifter loops in blobs tend to be larger than loopers in rings, reaching $500 \mathrm{~km}$ in overall size. Blobs tend to have equivalently swift surface velocities $\sim 50 \mathrm{~cm} / \mathrm{sec}$.

Blobs are interpreted to be large newly formed Agulhas rings located in the southeastern Cape Basin that are evolving in time and changing shape. The changes could be because blob-like rings are unstable or because they are located in a highly dynamic region and are interacting energetically with other rings, Agulhas cyclones and current filaments. In 5 cases drifter trajectories in blobs became more circular with time and eventually were classified as loopers. This suggests that blobs typically become more circular with time or alternatively that a smaller more circular part separates from the original blob (or possibly both). This latter inference is consistent with the results of Schouten et al. (2000) who found numerous rings to bifurcate in the Cape Basin. Since blobs can be significantly larger than most rings tracked with loopers, a much larger leakage per ring can be accomplished by blobs. For example, the formation of one $400 \mathrm{~km}$ blob is approximately equal in volume transport to 2.6 rings $250 \mathrm{~km}$ in diameter. This suggests that some large blob-like rings could bifurcate with each of the two split-off rings being at least $250 \mathrm{~km}$ in diameter. 
Float trajectories are not as informative about blobs as drifter trajectories. This is probably because float swirl velocities in rings are slower than drifter velocities and floats could not keep up with the rapidly evolving shape and structure of blobs. Floats do not appear to be easily trapped in blobs and are not able complete many loops in them. Details of a well-measured bloblike ring are discussed in Appendix C.

\subsection{Ring Leakage transport}

Evidence from drifters, floats, altimetry, and shipboard measurements clearly shows that rings are derived from the Agulhas and are an important contribution to Agulhas leakage. All the KAPEX rings tracked by drifters and floats were also tracked by altimetry (Schouten et al., 2005; see also Garzoli et al., 1999; Schmid et al., 2003), which provided some longer ring trajectories including back in time to ring formation. The two techniques give similar ring trajectories. Drifters and floats provide the additional important information that rings transport large amounts of (partially) trapped water.

In order to estimate ring leakage transport, the volume transport of a typical ring based on drifter and float data was combined with an estimate of ring formation rate based on altimetry. If each ring has a maximum diameter of trapped water of $250 \mathrm{~km}$, as observed with looping drifters and floats in the northwestern Cape Basin, then the estimated annual average volume transport associated with a ring formation is $1.6 \mathrm{~Sv}^{1}$ in the upper $1,000 \mathrm{~m}$. Perhaps a better model of ring structure is a truncated inverted cone, $250 \mathrm{~km}$ in diameter at the surface and $200 \mathrm{~km}$ in diameter at $1,000 \mathrm{~m}$. This shape models the smaller swirl velocity and smaller trapped area at 1,000 $\mathrm{m}$. The formation of one such ring per year amounts to 1.3 Sv. Using altimetry from 1993-1998, which overlaps many of our tracked rings, Schouten et al. (2000) found that 5.0 rings/year form from the retroflection and that some of these split, generating a total of 8.25 rings/year in the northwestern Cape Basin. Multiplying the individual ring transports given above by 8.25 rings/year gives a total annual ring volume transport of 10.4 to12.8 Sv. Clearly these values depend on the formation rate of rings, which varies somewhat from year to year, and depends on their diameters, which vary from ring to ring. Some of the blob-like rings in the southeast appear to be significantly larger than $250 \mathrm{~km}$, but some of the rings that bifurcated in the northern Cape Basin

\footnotetext{
${ }^{1}$ A rule of thumb for eddy volume transport is that the formation of one eddy per year, one hundred kilometers in radius, and one kilometer deep is equal to one Sverdrup (Sv).
} 
could be smaller than $250 \mathrm{~km}$. Therefore values of transport represent averages over several years.

The estimated ring leakage transport (10-13 Sv) is interpreted to be a large part (but not all) of the total leakage, which includes additional transport due to the Agulhas extension $\sim 2.6 \mathrm{~Sv}$ (discussed below) and possibly additional surface flow and filaments. The 13-15 Sv sum of the two components, rings and Agulhas extension, is consistent with the 14-15 Sv estimated from individual leakage drifters and floats that directly entered the Benguela Current. These two estimates of leakage transport (13-15 Sv and 14-15 Sv) are interpreted to include overlapping but slightly different parts of the total leakage. Therefore, to the extent that they do not represent the same parts of leakage, the real total leakage could be somewhat larger than either one of these alone. This suggests that leakage transport is at least $15 \mathrm{~Sv}$.

A complication concerning ring transport is that drifters and floats in the southeastern Cape Basin usually did not remain trapped in the rings and cyclones very long, but instead made multiple contacts with different rings and cyclones, sometimes only passing around the periphery of an (inferred) eddy (Boebel et al., 2003; Richardson and Garzoli, 2003). The numerous entrainments and detrainments of drifters and floats by eddies suggest that water does not remain trapped in eddies very long in the southeastern Cape Basin, but instead is exchanged with water from other eddies and from outside of eddies in a vigorous mixing regime called the Cape Cauldron by Boebel et al. (2003). Indian Ocean water transported into the South Atlantic by Agulhas rings, cyclones, and filaments appears to be vigorously stirred and mixed by the eddy field with SAC water and tropical Atlantic water (see McDonagh et al. 1999). In such a turbulent regime Agulhas rings do not carry leakage water very far into the Atlantic before it becomes somewhat diluted. Therefore, transport of Indian Ocean leakage transport, estimated above for rings, is not carried by them unaltered through a background of western South Atlantic water. Instead the background water is a mixture of water from the Indian Ocean, Brazil Current, tropical Atlantic, and Drake Passage. Rings plus the turbulent background flow field transport the resulting mixture northwestward.

\subsection{Cyclones.}

The pattern of cyclone trajectories is very different from anticyclones. Most cyclones are located in the southeastern Cape Basin where they translated southwestward. Another smaller collection 
of cyclones, tracked by surface drifters near $30^{\circ} \mathrm{S}$, translated mainly westward. Drifter and float trajectories in the southeastern cyclones have some similarities. Specifically, many cyclones start near the Agulhas just west of the Agulhas Bank; these are interpreted to be Agulhas cyclones, which form on the northern side of the Agulhas south of Africa as either shear edge eddies or Natal Pulses and contain Indian Ocean water (Lutjeharms et al., 2003). Some cyclones in the southern Cape Basin might also have formed near the Agulhas retroflection and near rings that became unstable and separated into pieces. Presumably, these also would contain some Indian Ocean water. Because the thermocline is raised in the center of cyclones, they carry less warm and salty water than anticyclones, which have a depressed thermocline in their centers.

RAFOS floats tracked 3 Agulhas cyclones as they translated westward past $20^{\circ} \mathrm{E}$. They translated southwestward along the northern side of the Agulhas, adjacent to the African shelf, and entered the Cape Basin southwest of Cape Town. Fourteen floats looping in the three cyclones reached $20^{\circ} \mathrm{E}, 10$ of these floats in one cyclone. The general pattern observed by floats was first rapid $\sim 2$ day loops $(\mathrm{Ro}=0.9)$ with small diameter $\sim 20 \mathrm{~km}$ near the shelf. As the floats drifted westward, the loops usually increased in diameter and in period of rotation. Just west of the Agulhas bank the cyclonic vorticity seems to collect in an intense cyclone, which has been called a lee eddy (Lutjeharms et al, 2003; Penven et al. 2001). One lee eddy cyclone bifurcated into two cyclones, which translated southwestward. Peak swirl speeds in the lee eddy cyclone reached $50-60 \mathrm{~cm} / \mathrm{s}$, and the maximum diameter was around $200 \mathrm{~km}$. The minimum period of rotation of one cyclone was around 3 days $(\mathrm{Ro}=0.5)$.

These 3 Agulhas cyclones plus several other nearby cyclones tracked by floats translated southwestward in the Cape Basin at a mean velocity of $4.1 \mathrm{~cm} / \mathrm{s}$. However, two of these cyclones stalled near the Schmitt-Ott Seamount and another stalled west of the Agulhas which decreased the mean velocity somewhat. Seven drifters looping in cyclones in the same region have a mean translation velocity of $9.6 \mathrm{~cm} / \mathrm{s}$. It is not clear why surface cyclones appeared to translate faster since the cyclones are vertically coherent (see Boebel et al., 2003 and Lutjeharms et al., 2003); perhaps the velocity could be biased by the shorter drifter trajectories and larger drifter swirl velocities in the cyclones. The cyclones appear to decay somewhat from typical mean float swirl speeds of $30-40 \mathrm{~cm} / \mathrm{s}$ off Cape Town to $20-25 \mathrm{~cm} / \mathrm{s}$ for those farthest southwest, a distance of around $1200 \mathrm{~km}$; similarly, the minimum period of rotation increased from around 3 days off Cape Town $(\mathrm{Ro}=0.5)$ to 12 days $(\mathrm{Ro}=0.1)$ in the southwest. 
Surface drifters looping in what are interpreted to be Agulhas cyclones measured average swirl speeds of 40-60 cm/sec suggesting that the swirl speeds of cyclones and rings in the southeastern Cape Basin are roughly equivalent. One energetic cyclone near $37^{\circ} \mathrm{S} 13^{\circ} \mathrm{E}$ had a drifter and two floats looping in it at the same time and at approximately the same $\sim 200 \mathrm{~km}$ diameter. The surface swirl speed of this cyclone was around 2 times the float swirl speeds.

The trajectories of several cyclones stop near the Schmitt-Ott and Richardson Seamounts along the Agulhas ridge (Fig. 8). Drifters and floats stopped looping as the cyclones collided with these bathymetric features, indicating that the cyclonic circulation was disrupted. Some of the cyclones might have continued farther southwestward as weaker remnants after the drifters and floats were expelled. A few cyclones tracked by floats translated farther southwestward (to $5^{\circ} \mathrm{E}$ ) than those tracked by drifters. A possible explanation of this is that when the near surface flow in the cyclones encounters the relatively swift surface currents of the SAC plus Ekman drift the trapped volume in the cyclones is reduced, which tends to expel the drifters (Flierl, 1981). The expulsion of drifters would be enhanced as the swirl velocity of cyclones decayed in the southwest.

Not all of the cyclones in the southeastern Cape Basin were formed as Agulhas cyclones. This can be inferred from the cyclones that started farther north and translated southwestward. These cyclones tended to be less energetic that those farther south. Four of the northern cyclones tracked by floats started near Vema Seamount which has a minimum depth of $12 \mathrm{~m}$ near $31.7^{\circ} \mathrm{S}$ $8.3^{\circ} \mathrm{E}$ and which was identified by Schouten et al. (2000) as being where Agulhas rings tend to bifurcate. It is possible that cyclones form as part of ring bifurcation. Two of these cyclones tracked by floats translated northeastward and merged near $30^{\circ} \mathrm{S}$, followed by a predominantly westward translation up to the Walvis Ridge where the last float stopped looping.

Some of the cyclones observed with floats and altimetry seem to have originated near the eastern boundary, and most of them translated southwestward (Boebel et al., 2003; Morrow et al., 2004). It seems possible that they form as the flow along the eastern boundary becomes unstable and generates cyclones. Boebel et al. (2003) suggested that the cyclones could be related to interaction of Agulhas rings with the shelf, or to local upwelling along the shelf (Shannon and Nelson, 1996), or to an intermediate eastern boundary current along the shelf (Shannon and Hunter, 1988). Movies of sea level anomaly (MODAS) indicate energetic fluctuations starting near the retroflection and propagating up the west coast, with some fluctuations moving offshore (Boebel et al. 2003), implying that the Agulhas is the source of energy. 
Eight drifters looping in 6 different cyclones near $30^{\circ} \mathrm{S}$ translated westward. Four drifters in 2 cyclones roughly $300 \mathrm{~km}$ apart, began looping at almost the same time (August 1998) and were tracked simultaneously for 4 months. One of the two cyclones was tracked for a total of 14 months and almost 2,000 km as it crossed over the Walvis Ridge without any obvious disruption. All six cyclones were observed during the period May 1996-June 2003. They seem to start in the east near $13^{\circ} \mathrm{E}$ and end in the west near $17^{\circ} \mathrm{W}$, a distance of $2,900 \mathrm{~km}$. (One cyclone is located west of those shown in Fig. 5.) Their average westward translation velocity is $3.4 \mathrm{~cm} / \mathrm{s}$. The $30^{\circ} \mathrm{S}$ cyclones are energetic with average swirl speeds around $25 \mathrm{~cm} / \mathrm{sec}$, minimum periods of rotation of 4 days $(\mathrm{Ro}=0.5)$, and typical maximum diameters around $140 \mathrm{~km}$.

A possible origin of the $30^{\circ} \mathrm{S}$ surface cyclones is the bifurcation process of rings in the vicinity of Vema Seamount as was suggested for the cyclones tracked by floats near there. Agulhas rings have been observed by altimetry to interact with topography and break into smaller eddies (Schouten et al., 2000). Roughly half of the rings observed to split did so near Vema Seamount. It is possible that these rings generated attached cyclones as some models predict (see Matano and Beier, 2003) and that the cyclone and anticyclone (ring) could self-advect westward as a dipole. Two of the $30^{\circ} \mathrm{S}$ cyclones had a nearby anticyclone ( $200 \mathrm{~km}$ separation) observed with a looping drifter for part of their westward translation, one on the north side, the other on the south side. One of these cyclones translated westward as an accompanying ring (on the northeast side) translated northwestward. This could be a hint of a more general process since Schouten et al. (2000) show several nearly westward ring trajectories in this area. However, if the cycloneanticyclone dipoles are common, we should have observed more drifter anticyclonic loopers translating westward near the $30^{\circ} \mathrm{S}$ cyclone path. Assuming their origin is due to rings, then these cyclones might play a role in leakage by transporting Agulhas water that had been carried north in rings westward over the Walvis Ridge.

\subsection{Discussion of eddy translation}

The Cape Basin is not the only place where anticyclones translate equatorward and cyclones poleward. Morrow et al. (2004) find this pattern in the southeastern Indian Ocean where eddies form in the vicinity of the Leeuwin Current and in the northeastern Pacific where at least anticyclones translate equatorward. An example from the eastern North Atlantic are anticyclonic Mediterranean water eddies (meddies) that translate equatorward with some nearby cyclones 
translating poleward (Richardson et al., 2000). In the western Indian Ocean, de Ruijter et al. (2005) found that anticyclones and cyclones form off the southern tip of Madagascar and tend to disperse westward as observed in the Cape Basin. They appear to enter the Agulhas and translate downstream possibly triggering the shedding of Agulhas rings and cyclones. The different meridional translation direction of the eddies is primarily due to the $\beta$ effect (Cushman-Roisin, 1994; Morrow et al., 2004). Eddies can also be advected by the background flow field as in the case of Agulhas rings, and eddies can interact with and be advected by other nearby eddies.

\section{Agulhas extension}

An important new feature discovered here is a westward extension near $41^{\circ} \mathrm{S}$ from the Agulhas retroflection. Numerous floats drifted westward for various amounts of time in this current including six floats for long times (Fig. 9, Table 3). The six long-drifting floats indicate a westward flow near $41^{\circ} \mathrm{S}$ extending from the main retroflection out to at least $5^{\circ} \mathrm{W}$, a distance of around 2,000 km. Three RAFOS floats shown in Fig. 9 looped clockwise in three Agulhas cyclones as they translated southwestward as far as $6^{\circ} \mathrm{E}$ indicating a connection via discrete eddies between the Agulhas and its extension west of $6^{\circ} \mathrm{E}$. Part of the band of cyclones in Fig. 9 coincides with mean westward velocity vectors (shown later) suggesting that the cyclones contribute significantly to the mean velocity of this part of the extension.

ALACE float A507 drifted the whole way from the retroflection out to $5^{\circ} \mathrm{W}$ during $3 \frac{1 / 4}{4}$ years from December 1995 to March 1999 (Fig. 9). It followed the mean Agulhas retroflection out to around $16^{\circ} \mathrm{E}$, then continued westward and merged with the band of cyclones near $10^{\circ} \mathrm{E}$. This float indicates a direct connection between the retroflection and the Agulhas extension (west of the cyclones). The other five floats in Fig. 9 drifted westward along portions of the overall westward route at various times during this same period, suggesting the extension is a long-term ( $>3$ years) component of the circulation of this region. The average westward velocity of these 6 floats is 4-5 $\mathrm{cm} / \mathrm{s}$ (Table 3). At this rate water from the Agulhas could reach $5^{\circ} \mathrm{W}$ in around a year and a half.

Two other floats (not shown) drifted westward west of the area shown in Fig. 9 during October 1996 to November 1997. Although there is a gap between these two trajectories and those that end near $7^{\circ} \mathrm{W}$ (Fig. 9), the gap appears to be primarily a gap of float data in the Agulhas extension (see Fig. 3). The extension itself might at times continue another $1500 \mathrm{~km}$ westward across the mid-Atlantic Ridge to around $25^{\circ} \mathrm{W}$. 
The convoluted float trajectories (Figs. 3 and 9) in the vicinity of the extension suggest that the westward flowing water is mixed and blended with SAC water flowing eastward. A mean northward velocity of around $0.7 \pm 0.2 \mathrm{~cm} / \mathrm{s}$ is found in the Agulhas extension region $\left(0-10^{\circ} \mathrm{E}, 39\right.$ $\left.44^{\circ} \mathrm{S}\right)$. This implies that, in the mean, water in the extension passes northward into the northern branch of the SAC (centered near $38^{\circ} \mathrm{S}$ ) that feeds into the Benguela Current. The three floats in the extension west of $5^{\circ} \mathrm{E}$ (Fig. 9) drifted northwestward, indicating that the western limb of the extension feeds into the northern branch of the SAC (although one float eventually turned southward and drifted eastward south of the retroflection). In addition, several other RAFOS and ALACE floats tended to drift northward across the mean location of the extension as part of timedependent motions there which are around 7 times larger than the mean westward velocity in the extension $\left(0-10^{\circ} \mathrm{E}\right)$.

Volume transport of the Agulhas extension was estimated from float velocities and cyclone properties. In the east the contribution from Agulhas cyclones was estimated to be around $2.5 \mathrm{~Sv}$ based on the formation of around 6 cyclones/year observed with altimetry (Boebel et al., 2003), each one $130 \mathrm{~km}$ in diameter as estimated from looping floats (Table 3) and altimetry, and a thickness of $1,000 \mathrm{~m}$. Not all of this transport goes very far west since several floats in the cyclones stopped looping near the Schmitt-Ott Seamount and eventually went eastward south of the Agulhas. However, some cyclone transport went into the background flow field, and there is some westward transport outside of cyclones as indicated by float A507 (Fig. 9).

Between $5^{\circ} \mathrm{W}-5^{\circ} \mathrm{E}$ floats in the extension (Fig. 9) meander and loop over a latitude extent of a few degrees. The mean eastward velocities in Fig. 10 indicate the width of the average extension (0$\left.10^{\circ} \mathrm{E}\right)$ is around two degrees in latitude $(\sim 220 \mathrm{~km})$ and that the average westward velocity (and standard error) over this width using all available data is $1.2 \pm 0.4 \mathrm{~cm} / \mathrm{s}$. The transport estimated using this velocity, a width of $220 \mathrm{~km}$ and a vertical thickness of $1,000 \mathrm{~m}$ is $2.6 \pm 0.9 \mathrm{~Sv}$. A transport of $\sim 2.6 \mathrm{~Sv}$ is a smaller but still significant amount of Indian Ocean leakage relative to the estimates given above using leakage drifters and floats (14-15 Sv) and by combining yearly formation rates of rings and their overall (trapped) diameters (10-13 Sv).

Since the average westward velocity could have included some meandering eastward-drifting floats located in the swifter $(\sim 5-7 \mathrm{~cm} / \mathrm{s})$ SAC located north and south of the extension, the estimated average velocity of the extension is probably a lower bound. The $4-5 \mathrm{~cm} / \mathrm{s}$ average 
westward velocity of the 6 floats listed in Table 3 is significantly larger than the average westward velocities in Fig. 10. A simple model indicates how the apparent average velocity and transport could be reduced by meanders. Consider a $4 \mathrm{~cm} / \mathrm{s}$ westward jet, $2^{\circ}$ in latitude wide, embedded in a $6 \mathrm{~cm} / \mathrm{s}$ eastward current. The jet's transport averaged over a vertical thickness of $1,000 \mathrm{~m}$ would be $8.8 \mathrm{~Sv}$. If the jet meanders linearly north and south $1^{\circ}$ in latitude on either side of its mean location, then the mean westward velocity in the $2^{\circ}$ band coinciding with the mean jet location would be reduced to $1.5 \mathrm{~cm} / \mathrm{s}$, a reduction of $62 \%$. The mean westward transport in this $2^{\circ}$ band would be similarly reduced to $3.3 \mathrm{~Sv}$.

The Agulhas extension does not appear in velocity maps generated in a recent study of the circulation of the South Atlantic that grouped the same float data into $3^{\circ}$ latitude bins (NúñezRiboni et al., 2005). A minimum in the SAC is observed at the latitude of the extension but not westward flow. This is because the $3^{\circ}$ bins are larger than the $2^{\circ}$ width of the extension, and averages of velocity include relatively swift eastward flows located north and south of the extension, which overwhelm the slower westward velocities of the extension.

Five hydrographic sections cross the latitude of the Agulhas extension and show westward velocity near $41^{\circ} \mathrm{S}$ : SAVE4 near $13^{\circ} \mathrm{W}$ (Gordon et al., 1992), WOCE A14 near $9^{\circ} \mathrm{W}$ (Mercier et al., 2003), WOCE A11 near $5^{\circ} \mathrm{W}$ (Saunders and King, 1995), AJAX near $1^{\circ} \mathrm{E}$ (Whitworth and Nowlin, 1987), and WOCE A12 near $10^{\circ} \mathrm{E}$ (http://whpo.ucsd.edu). Geostrophic velocity derived from these hydrographic sections indicates westward flow extending from intermediate water depths up to the surface near $41^{\circ} \mathrm{S}$ and amounting to typically $5 \mathrm{~Sv}$ over the upper $1000 \mathrm{~m}$. These sections represent synoptic measurements of the currents and are spread out in longitude and time. They tend to confirm the pattern of float velocities and indicate that the mean transport estimated from floats is conservative. Clearly, a directly measured vertical profile of mean velocity is required for an improved estimate of total transport.

Surface drifters do not drift very far westward in the vicinity of the extension near $41^{\circ} \mathrm{S}$. The mean drifter velocity is eastward, a minimum of $5 \mathrm{~cm} / \mathrm{s}$ at $42^{\circ} \mathrm{S}$ centered between maxima of 13 $\mathrm{cm} / \mathrm{s}$ in the northern SAC and $20 \mathrm{~cm} / \mathrm{s}$ in the southern SAC (Fig. 11). The minimum drifter velocity matches perfectly the latitude of the maximum westward current measured by floats. The lack of a mean westward surface current is probably a result of Ekman current, Stokes drift, and drogue slip in the direction of the eastward mean wind velocity. When the wind-correlated part of drifter velocity is removed, a westward velocity of $1.3 \pm 1.9 \mathrm{~cm} / \mathrm{s}$ is found located at $42^{\circ} \mathrm{S}$ (Fig. 
11). Although this velocity is smaller than the standard error, considering the errors involved in the correction, it seems possible that the geostrophic flow immediately below the wind-forced layer could be weakly westward like that measured by floats. A possible explanation for the lack of significant westward geostrophic velocity in the extension (Fig. 11) is that (as was suggested for the deeper extension) a meandering westward near-surface jet is obscured in the mean by the inclusion of some swifter eastward velocities from the nearby SAC.

The trajectories of floats in the extension (Fig. 9) coincide with some major seamounts, which suggests a possible connection. Two floats drifted westward near the Discovery Seamounts, located near $1^{\circ} \mathrm{E} 42^{\circ} \mathrm{S}$, which rise up to a depth of $426 \mathrm{~m}$ below the sea surface. The same two floats continued northwestward and passed near the RSA Seamount, located near $6^{\circ} \mathrm{W} 40^{\circ} \mathrm{S}$, with a minimum depth of $260 \mathrm{~m}$. Just west of this seamount are Gough Island and McNish Seamount with a minimum depth of $150 \mathrm{~m}$. It is possible that the seamounts and island partially block the eastward flow in the SAC or cause it to bifurcate into two jets enabling the Agulhas extension to flow westward there.

A possible forcing mechanism (Rhines, 1977; Boudra and de Ruijter, 1986; Nakano and Hasumi, 2005) for the extension are the energetic current fluctuations in the vicinity of the Agulhas retroflection--the southwestward translations of Agulhas cyclones, the periodic advancing and retreating of the retroflection, and ring formations (Fig. 1). Another possibility, suggested by Mike Spall (personal communication), is that two meandering eastward jets separated by a gap (the extension) could generate westward recirculations in the gap between jets. Modeling studies reported by deRuijter et al. (1999) and Boudra and de Ruijter (1986) suggest that, although a major part of the Agulhas retroflects, there is a leakage component which first flows westward, eventually bending northward to connect to the South Atlantic subtropical gyre (as was observed with floats). This results in the branching of the SAC. The northern branch would be part of the South Atlantic subtropical gyre, and the southern branch could be the southern edge of the supergyre, which connects the subtropical gyres of the South Atlantic and South Indian Oceans.

\section{Maps of mean velocity}

\subsection{Surface drifter velocity}


Surface drifter velocities were used to generate a high-resolution $1^{\circ} \times 1^{\circ}$ map of mean drifter surface velocity (Fig. 12). Clearly apparent is the mean Agulhas Current which flows southwestward to around $18^{\circ} \mathrm{W} 40^{\circ} \mathrm{S}$ where it retroflects southward and eastward. The maximum mean speed in the Agulhas south of Africa is around $100 \mathrm{~cm} / \mathrm{sec}$. Some westward (red) velocity vectors peel off from the Agulhas near Cape Town and enter the Benguela Current, which is defined to be the northwestward flow along the west coast of Africa. This Agulhas leakage is joined by flow from the northern part of the broad eastward flowing SAC (34-39 $\mathrm{S})$. The Benguela Current consists of a band of relatively swift velocities, reaching $20-25 \mathrm{~cm} / \mathrm{s}$, which extends around $700 \mathrm{~km}$ off the southwestern coast of Africa (near $32^{\circ} \mathrm{S}$ ). The band continues northward to around $20^{\circ} \mathrm{S}$ where velocities are westward at around $15-20 \mathrm{~cm} / \mathrm{s}$ in the Benguela extension. A world-wide map of streamlines based on drifter velocities (Maximenko and Niiler, 2005) shows how the surface currents in our area of interest fit into the over all pattern of surface circulation.

Between $25-34^{\circ} \mathrm{S}$ west of $0^{\circ} \mathrm{W}$ the mean surface velocity is low and generally westward. Several Agulhas rings and a few cyclones translated through this region (Fig. 7), so some of the structure seen in the westward velocities is caused by rings and cyclones. This is especially noticeable in the geostrophic velocity profile between $23-31^{\circ} \mathrm{S}$ (Fig. 11). The boundary between the weak westward velocities of the Benguela region and the eastward velocities in the SAC lies near $30^{\circ} \mathrm{S}$ in the west and $35^{\circ} \mathrm{S}$ in the east; thus the boundary slopes southward toward the east. The eastward flow of near surface water between $30-35^{\circ} \mathrm{S}$ in the west lies over westward flow of intermediate water at $800 \mathrm{~m}$. The band of eastward drifter velocities in the SAC south of around $40^{\circ} \mathrm{S}$ appears to continue eastward south of the Agulhas.

The drifter velocity map shows that virtually all the mean near surface Benguela Current was observed during the BEST experiment, which instrumented a line along $30^{\circ} \mathrm{S}$, between the Walvis Ridge $\left(3^{\circ} \mathrm{E}\right)$ and the African coast. The observed transport of the Benguela Current during BEST was well measured to be $13 \mathrm{~Sv}$ in the upper $1000 \mathrm{~m}$ (Garzoli et al, 1996). This value is slightly less than half the transport of the Benguela extension estimated during KAPEX $~ 30 \mathrm{~Sv}$ (Richardson and Garzoli, 2003). The difference is due to rings and intermediate water which pass northwestward around the offshore end of the BEST line $\left(3^{\circ} \mathrm{E} 30^{\circ} \mathrm{S}\right)$ as shown in the float velocity map. This missed flow led to the low leakage transport $\sim 4 \mathrm{~Sv}$ based on BEST measurements. 
A map of geostrophic velocity was generated but is not shown. This is because the pattern of geostrophic velocities is very similar to that of the drifter velocities (Fig. 12), with the exception that geostrophic velocities are much smaller than those in Fig. 12 in the vicinity of the SAC, Benguela Current, and Benguela extension (see Fig. 11). The large scale mean winds are in the same general direction as the geostrophic flow-eastward over the SAC, northwestward over the Benguela Current, and westward over the Benguela extension in the mid-Atlantic (near $20^{\circ} \mathrm{N}$ ). The local winds in these regions drives a near surface current with a significant component $(\sim 5-7$ $\mathrm{cm} / \mathrm{s}$ ) in the direction of the geostrophic velocity. A major exception to this is the Agulhas and its extension where the mean wind velocity is counter to surface currents. The pattern of geostrophic velocities agrees, in general, with the surface flow field indicated by the mean dynamic topography derived using drifters, altimetry and winds (Niiler et al., 2003; Maximenko and Niiler, 2005).

\subsection{Float velocity}


All available subsurface float velocities in the vicinity of the intermediate water near a depth of $800 \mathrm{~m}(500 \mathrm{~m}$ to $1100 \mathrm{~m})$ were used to generate a high-resolution $1^{\circ} \times 1^{\circ}$ map of mean velocity vectors (Fig. 13). The Agulhas Current flows southwestward along the coast of Africa reaching $18^{\circ} \mathrm{E} 40^{\circ} \mathrm{S}$ where most of the water retroflects southward and returns eastward as the Agulhas Return Current. Fastest mean velocities are around $35 \mathrm{~cm} / \mathrm{s}$ south of Africa. In this region the 12 fastest daily float speeds surpassed $100 \mathrm{~cm} / \mathrm{s}$ with two reaching $130 \mathrm{~cm} / \mathrm{s}$. Part of the mean retroflection extends farther west to around $14^{\circ} \mathrm{E}$, possibly as rings pinched off from the main current. A band of (fairly noisy) red arrows near $39-42^{\circ} \mathrm{S}$ extends from the mean retroflection westward to around $5^{\circ} \mathrm{W}$ indicating the Agulhas extension that was more visible in Figs. 9 and 10.

Some mean flow from the Agulhas enters the Benguela Current as Agulhas rings although the velocity vectors are noisy near the retroflection due to intense Agulhas cyclones and rings. A band of fairly noisy red arrows extends from the Agulhas near $39^{\circ} \mathrm{S} 18^{\circ} \mathrm{E}$ northwestward into the Benguela. A few blue arrows near the southwestern point of Africa near Cape Town indicate an apparent flow into the Agulhas. These vectors match the northeastern side of several Agulhas cyclones tracked with floats near there. When averaged, float velocities in the southeastward swirl velocity region of the cyclones give the false impression of mean inflow to the Agulhas there. Farther southwest, the components of swirl velocity normal to the cyclone translation direction tend to cancel as the cyclones pass through the region.

Because of the large velocity variance in the vicinity of the retroflection, velocity vectors tend to have a large uncertainty, which makes them problematic for estimating leakage. Grouping data into larger bins tends to reduce the uncertainty somewhat but does not resolve narrow current features (see Núñez-Riboni et al., 2005). Boebel et al. (2003) mapped the KAPEX float velocities at a $3^{\circ} \times 3^{\circ}$ grid and estimated a leakage transport of order $9 \mathrm{~Sv}$ for the intermediate water layer (600 m thick) and a minor inflow from the Atlantic. An upward extrapolation of this transport per unit depth gives a value of $15 \mathrm{~Sv}$ for the upper $1,000 \mathrm{~m}$, which agrees with leakage transport estimated using other methods as described above.

The SAC flows eastward south of about $35^{\circ} \mathrm{S}$ in two branches, a northern one centered near $38^{\circ} \mathrm{S}$ (between $5^{\circ} \mathrm{W}-5^{\circ} \mathrm{E}$ ) and a southern one centered near $44^{\circ} \mathrm{S}$ (Fig. 13). The northern branch feeds into the Benguela Current east of around $0^{\circ} \mathrm{W}$ merging with Agulhas leakage. The two branches of the SAC are also seen in the maps of surface drifter velocity (Fig. 12) and coincide with 
maxima of sea surface temperature gradients as measured by satellite (Burls and Reason, 2006). Specifically, the northern branch of the SAC coincides with the subtropical frontal region, which contains the northern $\left(\sim 35^{\circ} \mathrm{S}\right)$ and southern $\left(\sim 38^{\circ} \mathrm{S}\right)$ subtropical fronts, and the southern branch of the SAC coincides with the sub-Antarctic front (Burls and Reason, 2006). The Agulhas extension lies in the region of very low surface temperature gradients between these frontal regions.

Two bands of relatively swift northwestward velocities $\sim 5-7 \mathrm{~cm} / \mathrm{s}$ are embedded in the broad Benguela Current and cross over the Walvis Ridge. These bands appear to be generated by Agulhas rings, whose translation velocity is somewhat faster than mean background velocities. In addition, the northwestward swirl velocity located on the northeastern side of the rings adds to the ring translation velocity and tends to cause faster mean velocities, especially where several rings translate near each other (Fig. 7). The main Benguela Current at $800 \mathrm{~m}$ lies around $600 \mathrm{~km}$ offshore of the African coast and is separated from the coast by mainly weak southeastward velocities along the boundary as measured by three floats at latitudes of $21-36^{\circ} \mathrm{S}$. Therefore, much of the high velocity region of the surface Benguela, measured with drifters, is located over a band of slow southeastward $800 \mathrm{~m}$ velocity. This band is considered to be part of the southward flow of tropical Atlantic water as mentioned by Richardson and Garzoli (2003; see Gordon et al., 1995). In addition, maximum velocities in the surface Benguela extension are near $20^{\circ} \mathrm{S}$ located over generally eastward velocity at $800 \mathrm{~m}$. At $20^{\circ} \mathrm{W}$ the maximum flow at $800 \mathrm{~m}$ in the Benguela extension is between $23-34^{\circ} \mathrm{S}$ well south of the near-surface Benguela extension (Fig. 12). Therefore, Agulhas leakage of intermediate water at $800 \mathrm{~m}$ passes underneath the near surface Benguela Current.

\subsection{Surface drifter eddy kinetic energy}

A map of drifter EKE reveals highest values, colored red, in the vicinity of the Agulhas and retroflection (Fig. 14). Ten bins had values greater than $3,000 \mathrm{~cm}^{2} / \mathrm{s}^{2}$ there; the maximum was $3,650 \mathrm{~cm}^{2} / \mathrm{s}^{2}$ near $39^{\circ} \mathrm{S} 19^{\circ} \mathrm{E}$. The EKE of the Agulhas retroflection area is considerably higher than elsewhere in the Atlantic as measured with drifters. For example, the highest value in the Gulf Stream is $2,790 \mathrm{~cm}^{2} / \mathrm{s}^{2}\left(1^{\circ} \times 1^{\circ}\right.$ bin) with only two values above $2,500 \mathrm{~cm}^{2} / \mathrm{s}^{2}$ (Fratantoni, 2001). The Loop Current in the Gulf of Mexico has a peak value near $2,000 \mathrm{~cm}^{2} / \mathrm{s}^{2}$, and the highest value in the tropical Atlantic is near $1,300 \mathrm{~cm}^{2} / \mathrm{s}^{2}$ (Fratantoni, 2001). World maps of EKE based on drifter data (N. Maximenko and P. Niiler, personal communication) and altimetry 
(Ducet et al., 2001) show that the retroflection region has the highest values of any western boundary current. These distributions of EKE agree in general with that shown in Fig. 14.

Highest EKE values in the retroflection (red) are surrounded by relatively high values colored yellow (500-1000 $\left.\mathrm{cm}^{2} / \mathrm{s}^{2}\right)$ including a swath extending northwest from the Agulhas through the southern Cape Basin (Fig. 14). This swath coincides with numerous drifters looping in eddies there (Fig. 5). The high values of EKE and low mean velocity there are indications of large eddy induced stirring. West of the yellow swath is a green area of EKE $\sim 250 \mathrm{~cm}^{2} / \mathrm{s}^{2}$ extending from $25-45^{\circ} \mathrm{S}$ coinciding with many ring trajectories and indicating the effect of ring swirl velocities at very long distances from the formation region. North of $25^{\circ} \mathrm{S}$, where the Benguela extension flows westward near $20^{\circ} \mathrm{S}$, are very low values (blue) around $100 \mathrm{~cm}^{2} / \mathrm{s}^{2}$. The distribution of EKE is similar to one shown by Boebel et al. (2003) who used satellite altimetry to calculate geostrophic velocities for the same region.

\subsection{Float eddy kinetic energy}

The large scale pattern of EKE in the float map (Fig. 15) is similar to the drifter map, although the values of float EKE are much lower than the drifter EKE values. This is partly due to reduced energy of currents and eddies measured by floats in the intermediate water and partly due to including ALACE-type floats, which do not fully resolve mesoscale motions and cut off higher frequency components. Another map (not shown) was generated using just high-resolution RAFOS float data, but it covers a much smaller area because they are concentrated near the retroflection and Cape Basin. Where they overlap, the map is similar to Fig. 15 but has somewhat higher values as mentioned below.

Maximum EKE from floats in the Agulhas retroflection region (Fig. 15) is around $500 \mathrm{~cm}^{2} / \mathrm{s}^{2}$ and from just RAFOS floats around $800 \mathrm{~cm}^{2} / \mathrm{sec}^{2}$. This is approximately $25 \%$ of the maximum EKE from drifters $\left(\sim 3000 \mathrm{~cm}^{2} / \mathrm{s}^{2}\right)$ and is in agreement with vertical profiles of EKE based on moored current meter measurements in the retroflection region (Schmitz, 1996). Yellow regions of relatively high values $\sim 100-200 \mathrm{~cm}^{2} / \mathrm{s}^{2}$ extend both southwestward toward $45^{\circ} \mathrm{S} 5^{\circ} \mathrm{E}$, where some yellow bins match two cyclones, and northwestward through the southern Cape Basin to $33^{\circ} \mathrm{S}$ $6^{\circ} \mathrm{E}$ where some yellow bins match another two cyclones. Two green bands $\sim 50 \mathrm{~cm}^{2} / \mathrm{s}^{2}$ continue northwestward coinciding with locations of some rings tracked there (Fig. 7) and also coinciding with some fast average mean velocities shown in Fig. 13. These two green bands fade to blue 
$25 \mathrm{~cm}^{2} / \mathrm{s}^{2}$ near the Walvis Ridge, the northwestern boundary of the Cape Basin. (The Walvis Ridge cuts diagonally across the figures, from upper right to lower left, see Figs. 5-8.) In these regions the RAFOS EKE values are around 10 to $30 \%$ larger than those in Fig. 15. A third region of green values is located near $45^{\circ} \mathrm{S} 0-10^{\circ} \mathrm{W}$ coinciding with fast speeds in the SAC. In the north and west are low EKE values $\sim 5-10 \mathrm{~cm}^{2} / \mathrm{s}^{2}$ colored blue.

Boebel et al. (2003) also mapped EKE of the KAPEX region using RAFOS float data and found some similar values although his $2^{\circ} \times 2^{\circ}$ bin averages did not resolve very well the maximum in the retroflection region. Davis (2005) used ALACE float velocities near $900 \mathrm{~m}$ depth to map eddy diffusivity ( $\sim 3^{\circ}$ bins) in the Indian and Pacific oceans including the southeastern corner of the Atlantic. He found the largest diffusivity to be in the Agulhas retroflection region.

In summary, the patterns of EKE from drifters and floats are similar although the RAFOS float values are reduced by around a factor of 4 or so near the Agulhas retroflection. One difference between the maps is that floats tracked some Agulhas cyclones farther southwestward (to $5^{\circ} \mathrm{E}$ ) than did drifters, causing some local peaks of EKE there. The major swath of high EKE values extending northwestward through the Cape Basin in both maps appears to be caused by energetic Agulhas rings and cyclones observed by looping drifters and floats. Some rings continued long distances northwestward causing bands of high values of float EKE (green) there. EKE decreases considerably near the Walvis Ridge. Agulhas leakage passes through the energetic Cape Basin where high EKE and energetic eddies make the leakage difficult to measure and the mean velocity difficult to map at high resolution with the present limited data.

\section{Summary and conclusions}

The Agulhas Current sheds large anticyclonic rings and somewhat smaller cyclones, which drift westward into the South Atlantic contributing a major part of the total Indian Ocean leakage. Anticyclonic rings translate northwestward directly into the Benguela Current. Because of the energetic region in which they form, rings are often not very ring-like in the southeastern Cape Basin, and drifters and floats often do not remain trapped in these rings for very long. Most cyclones translate southwestward counter to the South Atlantic Current (SAC), so they do not translate as far as rings. The Cape Basin is an eddy crossroads with cyclones and anticyclones translating through it in different directions. This region is unique in that it is the only place on earth where cyclones and anticyclones shed from a major western boundary current enter the 
eastern part of an ocean basin and translate long distances westward. The Agulhas retroflection region is also unique in having the largest eddy kinetic energy and largest eddy diffusivity of all the western boundary currents.

Individual surface drifter and subsurface float trajectories were studied for evidence of Agulhas leakage. Four drifters and 5 floats that had been clearly drifting in the Agulhas Current drifted northwestward in the Benguela Current indicating a leakage of around 14-15 Sv. Because of the relatively small numbers of these leakage drifters and floats and possible problems of the measurements this transport could have a substantial error associated with it.

Looping trajectories (loopers) were used to identify cyclonic and anticyclonic eddies. Virtually all anticyclones were interpreted to be Agulhas rings. They follow a northwestward path from the retroflection region at a mean velocity around $4.4 \mathrm{~cm} / \mathrm{s}$ based on 5 rings, each tracked for over a year. Rings were found to be most energetic in the southeastern Cape Basin near the retroflection with maximum near surface swirl speeds of $60-135 \mathrm{~cm} / \mathrm{s}$. Surface swirl speed in rings decreased within the Cape Basin with an estimated e-folding distance of around $1300 \mathrm{~km}$. A comparison of drifter and float swirl speeds at the same approximate diameter and time in three rings indicates that surface swirl speeds are around 2-3 times faster than the speeds at $800 \mathrm{~m}$. Typical overall diameter of rings was $250 \mathrm{~km}$. The transport of a typical ring was combined with the annual formation rate of 8.25 rings/year as observed with altimetry (Schouten et al., 2000) to estimate a ring leakage transport of 10-13 Sv.

Several anticyclonic blob-like eddies were observed in drifter trajectories in the southeastern Cape Basin coinciding with rings. These anticyclonic blobs are interpreted to be Agulhas rings, but they are much less circular than most rings west of the Walvis Ridge. Because of the irregular and changing shape of the drifter "loops" they were not classified as loopers. These blob-like rings tended to be somewhat larger than the more-circular rings, reaching an overall size around $500 \mathrm{~km}$. Drifter loops in five blob-like rings became more circular in time and eventually were classified as loopers.

Most cyclones were located in the southeastern Cape Basin. Many of them are interpreted to be Agulhas cyclones, which form along the cyclonic shear region where the Agulhas flows along the southern boundary of Africa. Just west of the Agulhas Bank some energetic cyclones were observed with maximum surface swirl speeds of $50-60 \mathrm{~cm} / \mathrm{s}$ in a cyclonic lee eddy, indicating 
they are as energetic as rings. The maximum overall diameters of the cyclones were around 200 $\mathrm{km}$, and their surface swirl speeds were around 2 times faster than that at the intermediate water level. The minimum period of rotation ( $\sim 20 \mathrm{~km}$ diameter $)$ in the Cape Basin was around 3 days $($ Ro $=0.5)$. Agulhas cyclones translated southwestward through the southern Cape Basin at speeds of 5 to $10 \mathrm{~cm} / \mathrm{s}$, some reaching $5^{\circ} \mathrm{E}$, a distance of $1,200 \mathrm{~km}$.

Another group of cyclones was observed by 8 looping drifters near $30^{\circ} \mathrm{S}$. They translated westward along $30^{\circ} \mathrm{S}$ from $13^{\circ} \mathrm{E}$ to $17^{\circ} \mathrm{W}$, a distance of $2,900 \mathrm{~km}$, although no cyclone made the whole trip. These cyclones are quite energetic with maximum surface swirl speeds of $40 \mathrm{~cm} / \mathrm{s}$ and overall diameters of $140 \mathrm{~km}$. It is conjectured that they form from rings that bifurcate in the northern Cape Basin near Vema Seamount and translate westward as cyclone-anticyclone dipoles.

Several floats drifted westward near $41^{\circ} \mathrm{S}$ at around $4-5 \mathrm{~cm} / \mathrm{s}$ in a newly discovered westward flowing current, the Agulhas extension, that was traced from the Agulhas retroflection out to around $5^{\circ} \mathrm{W}$ and perhaps as far as $25^{\circ} \mathrm{W}$. Agulhas cyclones are inferred to contribute water to the extension. Water in the extension is blended with western Atlantic water, turns northeastward into the northern branch of the SAC, and enters the Benguela Current. Transport of the Agulhas extension was estimated to be at least $2.6 \mathrm{~Sv}$ in the upper $1,000 \mathrm{~m}$. This amount should be added to ring transport to estimate the total leakage of $13-15 \mathrm{~Sv}$.

A map of mean velocity generated using surface drifter data indicates that the SAC water and Agulhas leakage water merge off Cape Town and flow northward as an eastern boundary current along the coast of Africa, turning westward near $20^{\circ} \mathrm{S}$. A map of mean velocity derived from float data shows that the intermediate-depth $(\sim 800 \mathrm{~m})$ Benguela Current diverges westward from the near surface Benguela and passes over the mid-Atlantic Ridge between $22-35^{\circ} \mathrm{S}$, well south of the maximum westward surface velocity near $20^{\circ} \mathrm{S}$. Therefore intermediate-level Agulhas leakage passes underneath the near surface Benguela Current.

The total Agulhas leakage is at least $15 \mathrm{~Sv}$ based on float and drifter data. This is approximately equal to the $15 \mathrm{~Sv}$ of leakage found by Gordon et al. (1992) and the 15-16 Sv leakage found in two recent global ocean modeling studies (Speich et al., 2001; Donners and Drijfhout, 2004). These modeling studies also found that virtually all the upper layer MOC is comprised of leakage water. The implication is that most of the observed leakage enters the MOC joined by 1-2 Sv of Drake Passage water passing through the Atlantic. Part of the leakage is probably temporarily 
recycled in the subtropical gyre before continuing northward. It is possible that some leakage recirculates southward in the gyre and is exchanged with Drake Passage water in the SAC (Gordon et al., 1992). According to the simulations of Donners and Drijfhout (2004) this would be a small amount ( $2 \mathrm{~Sv}$ above 1,000 m), but Gordon et al. (1992) suggest it could amount to 6 Sv of the $15 \mathrm{~Sv}$ leakage.

Most of the Agulhas leakage is interpreted to pass northwestward in the South Equatorial Current and along the coast of Brazil in the swiftly flowing North Brazil Undercurrent and then North Brazil Current. At $11^{\circ} \mathrm{S}$ and $5^{\circ} \mathrm{S}$ the undercurrent has maximum speeds of $70-90 \mathrm{~cm} / \mathrm{s}$ centered at depths of 200-300 m, it extends from the near surface to around 1,000 $\mathrm{m}$ in depth and offshore around $100 \mathrm{~km}$, and it has a transport of $26 \mathrm{~Sv}$ (Schott et al., 2005). This transport is partially balanced by southward Ekman transport and offshore recirculations, leaving around $15 \mathrm{~Sv}$ to continue northward in the MOC, most of which is located in the upper $500 \mathrm{~m}$.

\section{Acknowledgements}

Contribution number 11388 from the Woods Hole Oceanographic Institution. Funds for this research were provided by National Science Foundation grants OCE-0236654 to the Woods Hole Oceanographic Institution and OCE-0236527 to the Woods Hole Research Center. Chris Wooding calculated statistical quantities and generated the figures. Amy Bower, Will de Ruijter, Andrea Doglioli, Chris Duncombe Rae and two anonymous reviewers provided constructive suggestions on an earlier version of the paper.

\section{Appendix A. Drifter and float measurement problems related to leakage}

Each of the float measurement techniques has certain problems, which should be considered when interpreting results. Surface drifters were drogued at $15 \mathrm{~m}$ in the wind-forced Ekman layer. The prevailing eastward mean wind velocity in the vicinity of the retroflection generates a northward velocity component in the Ekman layer which would tend to advect drifters and surface water northward out of the Agulhas and into the southern Cape Basin. Although the surface drifter trajectories are probably representative of the leakage in the Ekman layer, they could overestimate the leakage occurring below the Ekman layer. ALACE floats, which periodically rise to the surface, would also be influenced by northward flow in the Ekman layer while they drifted at the surface, although much less so than surface drifters because of the short 
times at the surface. Series of ALACE surface and subsurface displacements in the form of trajectories were used to infer leakage of intermediate water despite these trajectories being biased by periodic surface drifts. Therefore, estimates of leakage using ALACE float trajectories might also somewhat overestimate true leakage of intermediate water. Finally, RAFOS floats were launched predominantly in the northern half of the Agulhas, which seems to have caused a large number of them to be entrained into a few cyclones located there. This somewhat limited the number of independent realizations of the flow field. In addition, the resulting float trajectories appear to be strongly influenced by the behavior of the cyclones, which tended to translate southwestward and not northwestward into the Benguela. This is discussed further in Appendix B.

\section{Appendix B. RAFOS float details concerning leakage}

A detailed inspection of the RAFOS trajectories gives some clues about processes occurring near the retroflection. Of the first deployment of RAFOS floats in the Agulhas (December 3, 1997), 12 floats crossed $20^{\circ} \mathrm{E}$ in the Agulhas. Ten of these were entrained into and looped in an Agulhas cyclone on the northern side of the Agulhas. One of the two floats that did not loop was a leakage float. Only 6 floats of the second deployment in the Agulhas (June 13 and 15) reached $20^{\circ} \mathrm{E}$ in the Agulhas. Four were in two cyclones, one was in an anticyclone, and one, the second leakage float, did not loop. Therefore two of the 3 floats that did not loop near $20^{\circ} \mathrm{W}$ were leakage floats that entered the Benguela. Both of these appear to leave the Agulhas by drifting northward around the western side of cyclones that were translating westward as measured by looping floats. Both of these cyclones appear to have caused the pinching off of a ring to their north (Lutjeharms et al., 2003). One of two leakage floats looped in one of these rings off Cape Town just after leaving the Agulhas (Fig. 6). The other skirted around the periphery of a ring and continued north. The implication is that an Agulhas float is more likely to leave the Agulhas and enter the Benguela (becoming a leakage float) if the float was not looping in an Agulhas cyclone near $20^{\circ} \mathrm{E}$, and that cyclones strongly influence the behavior of floats by advecting the $\mathrm{m}$ across the mean boundary of the Agulhas. Two of the three Agulhas cyclones tracked by Agulhas floats near $20^{\circ} \mathrm{E}$ appear to have encountered the Schmitt-Ott Seamount and been deflected southward toward the retroflection. The third cyclone skirted northward around the seamount. Several floats stopped looping during the cyclones' encounters with this seamount and eventually went eastward south of the Agulhas. 


\section{Appendix C: Detailed example of a blob-like Agulhas ring}

An example of a well-measured blob-like ring was described by Schmid et al., (2003), Garzoli et al., (1999), and Richardson and Garzoli, (2003). This ring was observed by ship near $38^{\circ} \mathrm{S} 15^{\circ} \mathrm{E}$ in March 1997 and several RAFOS floats were launched in it (Schmid et al., 2003). None of these floats was classified as a looper although the collection of float trajectories and altimetry were used to follow the ring northwestward to June 1997. Starting in June and continuing through August 1997 a surface drifter made some irregular anticyclonic loops in the ring, including a large one $\sim 450 \mathrm{~km}$. The trajectory was so irregular that without altimetry we would not have known the drifter was in a ring. Superimposed on the $\sim 450 \mathrm{~km}$ irregular loop were small $\sim 30 \mathrm{~km}$ anticyclonic loops with fast rotation $\mathrm{T} \sim 6$ days $(\mathrm{Ro}=-0.3)$ indicating a smaller anticyclone was being advected by the larger scale (irregular) ring circulation. The rapid small scale looping seemed to become the core of the ring, which became more circular in September 1997.

In September as the drifter's loops became more circular the trajectory was classified as a looper. Also in September the ring was remeasured by ship, and 3 floats and 3 additional drifters were launched in it (Garzoli et al., 1999; Richardson and Garzoli, 2003). Some floats and drifters made numerous circular loops and are shown in Figs. 5 and 6. One float continued to loop for 18 months and only stopped because its mission ended. The main point is that this well-documented ring started out as an anticyclonic blob without identifiable loopers. At an age of 10 months it had evolved into a nearly circular ring which was subsequently tracked with looping floats and drifters for a long time (18 months).

\section{References}

Arhan, A., Mercier, H., Lutjeharms, J.R.E., 1999. The disparate evolution of three Agulhas rings in the South Atlantic Ocean. Journal of Geophysical Research 104 (C9), 20,987-21,005.

Beal, L.M., Bryden, H.L., 1999. The velocity and vorticity structure of the Agulhas Current at 32 S. Journal of Geophysical Research 104, 5151-5176. 
Boebel, O., Davis, R.E., Ollitrault, M., Peterson, R.G., Richardson, P.L., Schmid, C., Zenk, W., 1999b. The intermediate depth circulation of the western South Atlantic. Geophysical Research Letters 26 (21), 3329-3332.

Boebel, O., Duncombe Rae, C., Garzoli, S., Lutjeharms, J., Richardson, P., Rossby, T., Schmid, C., Zenk, W., 1998. Float experiment studies interocean exchanges at the tip of Africa. Eos, Transactions American Geophysical Union 79, 1,7-8.

Boebel, O., Lutjeharms, J.R.E., Schmid, C., Zenk, W., Rossby, T., Barron, C., 2003. The Cape Cauldron: a regime of turbulent inter-ocean exchange. Deep-Sea Research II, 50(1), 57-86.

Boebel, O., Schmid, C., Podesta, G., Zenk, W., 1999a. Intermediate Water in the Brazil-Malvinas Confluence Zone: a Lagrangian View. Journal of Geophysical Research 104(C9), 21,063-21,082.

Boudra, D.B., de Ruijter, W.P.M., 1986. The wind-driven circulation of the South Atlantic-Indian Ocean-II. Experiments using a multi-layer numerical model. Deep-Sea Research 33, 447-482.

Burls, N.J., Reason, C.J.C., 2006. Sea surface temperature fronts in the midlatitude South Atlantic revealed by using microwave satellite data. Journal of Geophysical Research 111, C08001, doi:10.1029/2005JC003133, 2006.

Byrne, D.A., Gordon, A.L., Haxby, W.F., 1995. Agulhas eddies: a synoptic view using Geosat ERM data. Journal of Physical Oceanography, 25, 902-917.

Cushman-Roisin, B., Chassignet, E.P., Tang, B., 1990. Westward motion of mesoscale eddies. Journal of Physical Oceanography 20, 97-113.

Davis, R., Webb, D.C., Regier, L.A., Dufour, J., 1992. The Autonomous Lagrangian Circulation Explorer. Journal of Atmospheric and Oceanic Technology 9, 264-285.

Davis, R.E., 2005. Intermediate depth circulation of the Indian and South Pacific Oceans measured by autonomous floats. Journal of Physical Oceanography 35(5), 683-707. 
de Ruijter, W.P.M., Biastoch, A., Drijfhout, S.S., Lutjeharms, J.R.E., Matano, R.P., Pichevin, T., van Leeuwen, P.J., Weijer, W., 1999. Indian-Atlantic interocean exchange: Dynamics, estimation and impact. Journal of Geophysical Research 104 (C9), 20,885-20,910.

De Ruijter, W.P.M., Ridderinkhof, H., Schouten, M.W., 2005. Variability of the southwest Indian Ocean. Philosophical Transactions of the Royal Society A 363, 63-76,

doi:10.1098/rsta.2004.1478.

Dogioli, A.M.,Veneziani, M., Blanke, B., Speich, S., Griffa, A., 2006. A Lagrangian analysis of the Indian-Atlantic interocean exchange in a regional model. Geophysical Research Letters 33, L14611, doi:10.1029/2006GL026498.

Donners, J., Drijfhout, S., 2004. The Lagrangian view of South Atlantic interocean exchange in a global ocean model compared with inverse model results. Journal of Physical Oceanography 34, 1019-1035.

Donohue, K.A., Firing, E., 2000. Comparison of three velocity sections of the Agulhas Current and Agulhas Undercurrent. Journal of Geophysical Research 105, 28,585-28,593.

Ducet, N., Le Traon, P.Y., Reverdin, G., 2000. Global high-resolution mapping of ocean circulation from TOPEX/Poseidon and ERS-1 and -2. Journal of Geophysical Research 105, $19,477-19,498$.

Duncombe Rae, C.M., 1991. Agulhas retroflection rings in the South Atlantic Ocean: An overview. South African Journal of Marine Science 11, 327-344.

Duncombe Rae, C.M., Garzoli, S.L., Gordon, A.L., 1996. The eddy field of the southeast Atlantic Ocean: A statistical census from the Benguela Sources and Transports Project. Journal of Geophysical Research 101(C5), 11,949-11,964.

Flierl, G.R., 1981. Particle motions in large-amplitude wave fields. Geophysical and Astrophysical Fluid Dynamics 18, 39-74. 
Garzoli, S.L., Goñi, G.J., Mariano, A.J., Olson, D.B., 1997. Monitoring the upper southeastern Atlantic transports using altimeter data. Journal of Marine Research 55, 453-481.

Garzoli, S.L., Gordon, A.L., 1996. Origins and variability of the Benguela Current. Journal of Geophysical Research 101, 897-906.

Garzoli, S.L., Richardson, P.L., Duncombe Rae, C.M., Fratantoni, D.M., Goñi, G.J., Roubicek, A.J., 1999. Three Agulhas Rings observed during the Benguela Current Experiment. Journal of Geophysical Research 104 (C9), 20,971-20,986.

Goñi, G.J., Garzoli, S.L., Roubicek, A.J., Olson, D.B., Brown, O.B., 1997. Agulhas ring dynamics from TOPEX/POSEIDON satellite altimeter data. Journal of Marine Research 55, 861883.

Gordon, A.L., 1985. Indian-Atlantic transfer of thermocline water at the Agulhas retroflection. Science 227, 1030-1033.

Gordon, A.L., 2001. Interocean exchange. In: Siedler, G., Church, J., Gould, J. (Eds.), Ocean Circulation and Climate. Academic Press. London, pp. 303-314.

Gordon, A.L., 2003. The brawniest retroflection. Nature 421, 904-905.

Gordon, A.L., Bosley, K.T., Aikman, III, F., 1995. Tropical Atlantic water within the Benguela Upwelling System at $27^{\circ} \mathrm{S}$. Deep-Sea Research I 42(1), 1-12.

Gordon, A.L., Haxby, W.F., 1990. Agulhas eddies invade the South Atlantic--evidence from GEOSAT altimeter and shipboard conductivity-temperature-depth survey. Journal Geophysical Research 95 (C3), 3117-3125.

Gordon, A.L., Weiss, R.F., Smethie, W.M.Jr., Warner, M.J., 1992. Thermocline and intermediate water communication between the South Atlantic and Indian Oceans. Journal of Geophysical Research 97 (C5), 7223-7240. 
Lutjeharms, J.R.E., 1996. The exchange of water between the South Indian and the South Atlantic. In: Wefer, G., Berger, W.H., Siedler, G., Webb, D. (Eds.), The South Atlantic: Present and Past Circulation. Springer. Berlin, pp. 125-162.

Lutjeharms, J.R.E., Boebel, O., Rossby, H.T., 2003. Agulhas cyclones. Deep-Sea Research II, 50(1), 13-34.

Matano, R.P., Beier, E.J., 2003. A kinematic analysis of the Indian/Atlantic interocean exchange. Deep-Sea Research II, 50(1), 229-249.

Maximenko, N.A., Niiler, P.P., 2005. Hybrid decade-mean global sea level with mesoscale resolution. In: Saxena, N. (Ed.), Recent Advances in Marine Science and Technology. PACON International, Honolulu, pp. 55-59.

McCartney, M.S., 1977. Subantarctic mode water. In: Angel, M.V. (Ed.), A Voyage of Discovery: George Deacon $70^{\text {th }}$ Anniversary Volume, Supplement to Deep-Sea Research. Pergamon Press, Oxford, pp. 103-119.

McDonagh, E.L., Heywood, K.J., Meredith, M.P., 1999. On the structure, paths, and fluxes associated with Agulhas rings. Journal of Geophysical Research 104(C9), 21,007-21,020.

Mercier, H., Arhan, M., Lutjeharms, J.R.E., 2003. Upper-layer circulation in the eastern Equatorial and South Atlantic Ocean in January-March 1995. Deep-Sea Research I 50, 863-887.

Morrow, R., Birol, F., 2004. Divergent pathways of cyclonic and anti-cyclonic ocean eddies. Geophysical Research Letters 31, L24311, doi:10.1029/2004GL0209974.

Nakano, H, Hasumi, H., 2005. A Series of Zonal Jets Embedded in the Broad Zonal Flows in the Pacific Obtained in Eddy-Permitting Ocean General Circulation Models. Journal of Physical Oceanography 35(4), 474-488. doi: 10.1175/JPO2698.1

Niiler, P.P., Maximenko, N.A., McWilliams, J.C., 2003. Dynamically balanced absolute sea level of the global ocean derived from near-surface velocity observations. Geophysical Research Letters 30(22), 2164, doi:10.1029/2003GL018628. 
Núñez-Riboni, I., Boebel, O., Ollitrault, M., You, Y., Richardson, P.L., Davis, R, 2005.

Lagrangian circulation of Antarctic Intermediate Water in the subtropical South Atlantic. DeepSea Research II 52(3-4), 545-564.

Olson, D.B., Evans, R.H., 1986. Rings of the Agulhas Current. Deep-Sea Research 33, 27-42.

Peeters, F.J.C., Acheson, R., Brummer, G.A., de Ruijter, W.P.M., Schneider, R.R., Ganssen, G.M., Ufkes, E., Kroon, D., 2004. Vigorous exchange between the Indian and Atlantic oceans at the end of the past five glacial periods. Nature 430, 661- 665 .

Penven, P., Lutjeharms, J.R.E., Marchesiello, P., Roy, C., Weeks, S.J., 2001. Generation of cyclonic eddies by the Agulhas Current in the lee of the Agulhas Bank. Geographical Research Letters 27, 1055-1058.

Peterson, R.G., Stramma, L., 1991. Upper-level circulation in the South Atlantic Ocean. Progress in Oceanography 26, 1-73.

Reid, J.L., 1989. On the total geostrophic circulation of the South Atlantic Ocean: Flow patterns, tracers, and transports. Progress in Oceanography 23, 149-244.

Rhines, P.B., 1977. The dynamics of unsteady currents. In: Goldberg, E.D., McCave, I.N., O’Brien, J.J., Steel, J.H., (Eds.), The Sea, vol 6. John Wiley. N. Y., pp. 189-318.

Richardson, P.L., Bower, A.S., Zenk, W., 2000. A census of Meddies tracked by floats. Progress in Oceanography 45, 209-250.

Richardson, P.L., Garzoli, S.L., 2003. Characteristics of intermediate water flow in the Benguela Current as measured with RAFOS floats. Deep-Sea Research II 50(1), 87-118.

Richardson, P.L., Lutjeharms, J.R.E., Boebel, O., 2003. Introduction to the "Inter-ocean exchange around southern Africa". Deep-Sea Research II 50(1), 1-12. 
Rintoul, S.R., 1991. South Atlantic interbasin exchange. Journal of Geophysical Research 96, 2675-2692.

Rossby, H.T., Dorson, D., Fontaine, J., 1986. The RAFOS system. Journal of Atmospheric and Oceanic Technology 3, 672-679.

Saunders, P.M., King, B.A., 1995. Oceanic fluxes on the WOCE A11 section. Journal of Physical Oceanography 25, 1942-1958.

Schmid, C., Boebel, O., Zenk, W., Lutjeharms, J.R.E., Garzoli, S.L., Richardson, P.L., Barron C., 2003. Early evolution of an Agulhas Ring. Deep-Sea Research II, 50(1), 141-166.

Schmid, C., Siedler, G., Zenk, W., 2000. Dynamics of intermediate water circulation in the subtropical South Atlantic. Journal of Physical Oceanography 30(12), 3191-3211.

Schmitz, Jr., W.J., 1995. On the interbasin-scale thermohaline circulation. Reviews of Geophysics 33(2), 151-173.

Schmitz, Jr., W.J., 1996. On the eddy field in the Agulhas Retroflection, with some global considerations. Journal of Geophysical Research 101, 16,259-16,271.

Schott, F.A., Dengler, M., Zantopp, R., Stramma, L., Fischer, J., Brandt, P., 2005. The Shallow and Deep Western Boundary Circulation on the South Atlantic at $5-11^{\circ} \mathrm{S}$. Journal of Physical Oceanography 35(11), 2031-2053.

Schouten, M.W., de Ruijter, W.P.M., van Leeuwen, P.J., Lutjeharms, J.R.E., 2000. Translation, decay, and splitting of Agulhas rings in the southeastern Atlantic Ocean. Journal of Geophysical Research 105 (C9), 21,913-21,925.

Shannon, L., Hunter, D., 1988. Notes on Antarctic Intermediate Water around southern Africa. Aouth African Journal of Marine Science 6, 107-117. 
Shannon, G., Nelson, G., 1996. The Benguela: large scale features and processes and system variability. In: Wefer, G., Berger, W.H., Siedler, G., Webb, D.J., (Eds.), The South Atlantic: Present and Past Circulation. Springer, Berlin Heidelberg, pp. 163-210.

Sloyan, B.M., Rintoul, S.R., 2001. Circulation, renewal, and modification of Antarctic Mode and Intermediate Water. Journal of Physical Oceanography 31, 1005-1030.

Snowden, D.P., Molinari, R.L., 2003. Subtropical cells in the Atlantic Ocean: An observational summary. In: Goni, G., Malanotte-Rizzoli, P., (Eds.), Interhemispheric Water Exchange in the Atlantic Ocean. Elsevier Oceanographic Series, Elsevier, pp. 287-312.

Speich, S., Blanke, B., Madec, G., 2001. Warm and cold water routes of an O.G.C.M. thermohaline conveyor belt. Geophysical Research Letters 28(2), 311-314.

Stramma, L., Peterson, R.G. 1989. Geostrophic transport in the Benguela Current region. Journal of Physical Oceanography 19, 1440-1448.

Stramma, L., England, M., 1999. On the water masses and mean circulation of the South Atlantic Ocean. Journal of Geophysical Research 104, 20,863-20,884.

Sybrandy, A.L., Niiler, P.P., 1991. WOCE/TOGA Lagrangian Drifter construction manual, SIO Ref. 91/6, WOCE Rep. 63. Scripps Institution of Oceanography, La Jolla, CA (58 pp).

Tsuchiya, M., Talley, L.D., McCartney, M.S., 1994. Watermass distributions in the western Atlantic; a section from South Georgia Island $\left(54^{\circ} \mathrm{S}\right)$ northward across the equator. Journal of Marine Research 52, 55-81.

Whitworth, III, T., Nowlin, W.D., 1987. Water Masses and Currents of the Southern Ocean at the Greenwich Meridian. Journal of Geophysical Research 92(C6), 6462-6476.

Wessel,P., Smith, W.H.F., 1998. New, improved version of the Generic Mapping Tool Released. EOS Transactions of the American Geophysical Union 79, 579. 
Zhang, D., McPhaden, M.J., Johns, W.E., 2003. Observational evidence for flow between the subtropical and tropical Atlantic: The Atlantic tropical cells. Journal of Physical Oceanography $33,1783-1797$.

\section{Tables}

Table 1. Numbers of Loopers

\begin{tabular}{lccc}
\hline & Cyclonic & Anticyclonic & Total \\
\hline Drifters & 18 & 29 & 47 \\
RAFOS Floats & 29 & 20 & 49 \\
ALACE Floats & 0 & 3 & 3 \\
Total & 47 & 52 & 99 \\
& & & \\
\hline
\end{tabular}

Table 2. Numbers of Eddies

\begin{tabular}{lcccc}
\hline & Drifters & RAFOS Floats & ALACE Floats & Total \\
\hline Cyclones & 17 & 17 & 0 & 33 \\
Anticyclones & 24 & 14 & 3 & 35 \\
Total & 41 & 31 & 3 & 68 \\
\hline
\end{tabular}

Totals were reduced by because one cyclone and 6 anticyclones were tracked by combinations of drifters and floats.

Table 3. Summary of six floats drifting westward for long times in the Agulhas extension. $U$ is the mean eastward velocity with standard error, A indicates non-acoustic ALACE-type floats, $R$ 
indicates acoustic RAFOS floats, and (I) indicates an isopycnal float. Floats R218, R222, and R485(I) looped in three cyclones along with several other floats not listed. The number of successive float loops in these three cyclones ranged between 8-15 loops, the periods of loops between 10-18 days, the maximum diameters of the loops between 130-200 km, and maximum swirl speeds between $24-55 \mathrm{~cm} / \mathrm{s}$. The largest diameter and fastest swirl speed were in the lee eddy cyclone located southwest of the Agulhas Bank which extends south of Africa.

\begin{tabular}{lccccccc}
\hline Float & $\begin{array}{c}\text { Start } \\
\text { (yymmdd) }\end{array}$ & $\begin{array}{c}\text { End } \\
\text { (yymmdd) }\end{array}$ & $\begin{array}{l}\text { Days of } \\
\text { Data }\end{array}$ & $\begin{array}{c}\mathrm{U} \\
(\mathrm{cm} / \mathrm{s})\end{array}$ & $\begin{array}{c}\text { Depth } \\
(\mathrm{m})\end{array}$ & $\begin{array}{c}\text { Temp } \\
\left({ }^{\circ} \mathrm{C}\right)\end{array}$ & Ro \\
\hline A507 & 951205 & 990309 & 1145 & $-2.9 \pm 0.4$ & 790 & 4.5 & \\
A362 & 970427 & 970922 & 135 & $-4.8 \pm 1.0$ & 930 & 3.2 & \\
R222 & 970610 & 971005 & 117 & $-3.7 \pm 5.2$ & 700 & 4.7 & 0.10 \\
R218 & 970701 & 980304 & 247 & $-3.8 \pm 3.1$ & 820 & 4.7 & 0.09 \\
R485(I) & 971210 & 980601 & 174 & $-8.6 \pm 7.1$ & 700 & 5.2 & 0.17 \\
R207 & 980501 & 981028 & 181 & $-4.6 \pm 0.9$ & 800 & 4.4 & \\
6 floats & 951205 & 990305 & 1999 & $-3.8 \pm 0.8$ & 790 & 4.5 & \\
grouped & & & & & & & \\
6 avgs & 951205 & 990305 & 1999 & $-4.7 \pm 0.8$ & 790 & 4.4 & \\
grouped & & & & & & &
\end{tabular}

\section{Figure captions}


Figure 1. Schematic map of the circulation of intermediate water based on float trajectories and other data. The Cape Basin is populated by numerous Agulhas rings (rotating counter clockwise) which pinch off from the Agulhas retroflection and numerous cyclonic eddies (rotating clockwise) many of which form along the northern boundary of the Agulhas south of Africa. The rings tend to translate northwestward and cyclones southwestward. Several floats drifted westward near $41^{\circ} \mathrm{S}$ indicating an extension of the Agulhas, which splits the South Atlantic Current into a northern and southern branch. This schematic view of discrete eddies is a simplification of the Cape Basin which is very complicated. This figure is an update of one shown by Richardson et al. (2003).

Figure 2. Summary of 321 surface drifter trajectories measured during 1994-2004 in the vicinity of southern Africa. Velocities (one per day) were color-coded to indicate speed. High speeds $>$ $50 \mathrm{~cm} / \mathrm{s}$ are located in the vicinity of the Agulhas retroflection south if Africa. An inspection of 6hourly drifter velocities in the vicinity of the Agulhas found 15 which exceeded $200 \mathrm{~cm} / \mathrm{s}$, the fastest reaching $233 \mathrm{~cm} / \mathrm{s}$. The Agulhas retroflection is the most energetic region on the planet (Ducet et al. 2001).

Figure 3. Summary of float trajectories at intermediate water depths centered near a depth of 800 $\mathrm{m}$ and within the depth range 500-1100 m. Red trajectories indicate isopycnal RAFOS floats launched in the Agulhas Current (Lutjeharms et al., 2003), green indicate quasi-isobaric RAFOS floats launched in the vicinity of the eastern South Atlantic Current (Boebel et al., 2003), blue indicate quasi-isobaric RAFOS floats launched in the vicinity of the Benguela Current and its extension (Richardson and Garzoli, 2003), and black vectors are subsurface displacements of ALACE floats (Davis, 2005). Red floats account for 11 float years, blue ones for 46 float years, green ones for 47 float years, and black ones for 86 float years. Most of the float trajectories were measured during the years 1996 to 2000, the RAFOS trajectories during March 1997 to September 1999. Arrowheads are spaced at 15 days along RAFOS trajectories and at the ends of subsurface ALACE displacements. Shaded regions indicate depths shallower than $1000 \mathrm{~m}$ (darkest shading), $2000 \mathrm{~m}, 3000 \mathrm{~m}$, and $4000 \mathrm{~m}$ (lightest shading).

Figure 4. Displacement vectors of 4 surface drifters (red), 2 RAFOS floats (blue) and 3 ALACEtype floats (green) that drifted westward across $20^{\circ} \mathrm{E}$ in the Agulhas Current and northwestward in the Benguela Current. Displacements vectors go from $20^{\circ} \mathrm{E}$ to the northwestern most point of 
each trajectory or to where they crossed $10^{\circ} \mathrm{W}$ or $20^{\circ} \mathrm{N}$. Displacements are shown because they are much less complicated than trajectories and clearly indicate general drift. They provide direct evidence of the leakage of the near surface and intermediate Agulhas water into the Atlantic.

Figure 5. Trajectories of surface drifters looping in discrete eddies. Blue trajectories indicate clockwise rotating cyclones and red trajectories indicate counter clockwise rotating anticyclones. Red trajectories are interpreted to have been in (mainly) warm core Agulhas rings, and the most southern group of blue trajectories in (mainly) Agulhas cyclones. Some additional, shorter, trajectories in the same eddies were omitted to reduce clutter as were a few short nearlystationary loopers. A few trajectories extended west of the left edge of the figure $\left(10^{\circ} \mathrm{W}\right)$.

Figure 6. Trajectories of subsurface floats looping in discrete eddies. Blue indicates cyclones and red anticyclones (as in Fig. 5). Two series of subsurface displacement vectors of ALACEtype floats that looped (jagged loops) in two Agulhas rings are shown despite the poor resolution of the eddy loops. Looping RAFOS floats in two of the three rings measured with ALACE floats confirm they were in rings. A few trajectories extended west of the left edge of the figure $\left(10^{\circ} \mathrm{W}\right)$.

Figure 7. Trajectories of anticyclones drawn manually through looping drifter and float trajectories. These are interpreted to be Agulhas rings except, possibly, a blue one translating northeastward near $0^{\circ} \mathrm{W} 44^{\circ} \mathrm{S}$ which looks anomalous compared to the usual northwestward paths and a blue one translating southwestward embedded in the Agulhas Current.

Figure 8. Trajectories of cyclones drawn manually through looping drifter and float trajectories. Many in the southeastern group of trajectories are interpreted to be Agulhas cyclones, which form along the northern edge of the Agulhas. The general trend is clearly southwestward translation except for several cyclones located near $30^{\circ} \mathrm{S}$, tracked mainly by drifters, which translate nearly westward, including one cyclone measured by a float.

Figure 9. Trajectories of four RAFOS floats (solid lines) and subsurface displacements of two ALACE-type floats (arrows), which drifted westward near $41^{\circ} \mathrm{S}$ and illustrate the Agulhas extension (see Table 3). Westward drifting portions of longer trajectories were selected to emphasize the extension. Only ALACE float A507 drifted all the way from the main Agulhas Current to $7^{\circ} \mathrm{W}$. This is roughly $2,000 \mathrm{~km}$ past the mean location of the Agulhas retroflection. 
Three RAFOS floats looped in three Agulhas cyclones showing their southwestward pathway to at least $6^{\circ} \mathrm{E}$ and suggesting a connection between the Agulhas current and the westward flow west of $6^{\circ} \mathrm{E}$.

Figure 10. Meridional profile of eastward currents measured by floats between $20-45^{\circ} \mathrm{S}$. The Benguela Current extension flows westward between $21-34^{\circ} \mathrm{S}$ with a maximum mean velocity around $6 \mathrm{~cm} / \mathrm{s}$. The higher speeds are caused by rings, which translate through the background flow field. The South Atlantic Current (SAC) flows eastward south of $35^{\circ} \mathrm{S}$ with maximum mean velocities around $5-7 \mathrm{~cm} / \mathrm{s}$. The Agulhas extension flows westward between $40.5-42.5^{\circ} \mathrm{S}$ with a peak mean velocity around $2 \mathrm{~cm} / \mathrm{s}$, splitting the SAC into two branches. The average velocity profile was calculated by grouping all available float velocity measurements in $1^{\circ}$ latitudinal strips in the band $0-10^{\circ} \mathrm{E}$, switching to $0-10^{\circ} \mathrm{W}$ north of $37^{\circ} \mathrm{S}$.

Figure 11. Meridional profile of eastward currents measured by surface drifters $20-45^{\circ} \mathrm{S}$ (similar to Fig. 10). North of around $32^{\circ} \mathrm{S}$ is the Benguela extension and south of $32^{\circ} \mathrm{S}$ is the SAC. A minimum of eastward velocity in the SAC centered near $42^{\circ} \mathrm{S}$ is interpreted to be the surface manifestation of the Agulhas extension observed by floats at this latitude (see text). The profile of geostrophic velocity on the right is the eastward drifter velocity after the local wind-correlated velocity component was removed. The noisy velocities in the Benguela extension $24-31^{\circ} \mathrm{S}$ are due to drifters looping in the swift swirl velocities of several rings and cyclones that translated westward in this region (see Fig. 5). The average velocity profiles were calculated by grouping all available float velocity measurements in $1^{\circ}$ latitudinal strips in the band $0-10^{\circ} \mathrm{E}$, switching to 0 $10^{\circ} \mathrm{W}$ north of $37^{\circ} \mathrm{S}$.

Figure 12. Mean velocity vectors calculated by grouping 6-hourly surface drifter velocity values into $1^{\circ} \times 1^{\circ}$ bins. Grey shading indicates vectors that are smaller than standard errors and areas of sparse data, fewer than 6 degrees of freedom. Red vectors indicate westward mean velocity and blue ones eastward mean velocity. The map shows northwestward mean velocities from the Agulhas into the Benguela, which flows along the west coast of Africa and then westward near $20^{\circ} \mathrm{S}$.

Figure 13. Mean velocity vectors calculated from subsurface floats drifting near a depth of $800 \mathrm{~m}$ (500-1100 m). Red indicates westward velocity and blue eastward velocity. Bands of relatively fast northwestward velocity located in the Benguela Current are due to the combination of ring 
translation and northwestward swirl velocities of several floats looping in Agulhas rings. The Agulhas extension is indicated by the (fairly noisy) band of red arrows that extends from the mean Agulhas retroflection westward near $41^{\circ} \mathrm{S}$, splitting the SAC into two branches. Grey shading indicates vectors that are smaller than standard errors and areas of sparse data, fewer than six degrees of freedom.

Figure 14. Eddy kinetic energy (EKE) estimated from drifter velocity variances in $1^{\circ} \mathrm{x} 1^{\circ}$ bins. High EKE values $\left(1500-3500 \mathrm{~cm}^{2} / \mathrm{s}^{2}\right)$ coincide with the Agulhas retroflection and southern Cape Basin where numerous eddies are observed. A band of high values $\left(300-1000 \mathrm{~cm}^{2} / \mathrm{s}^{2}\right)$ extends northwestward following the paths of rings up to the Walvis Ridge.

Figure 15. Eddy kinetic energy (EKE) estimated from float velocity variances in $1^{\circ} \mathrm{x} 1^{\circ}$ bins. Highest values of EKE $\left(300-500 \mathrm{~cm}^{2} / \mathrm{s}^{2}\right)$ coincide with the Agulhas retroflection and southern Cape Basin. A band of moderately high values $\left(80-200 \mathrm{~cm}^{2} / \mathrm{s}^{2}\right)$ extends northwestward from the retroflection towards the Walvis Ridge. 
Click here to download high resolution image

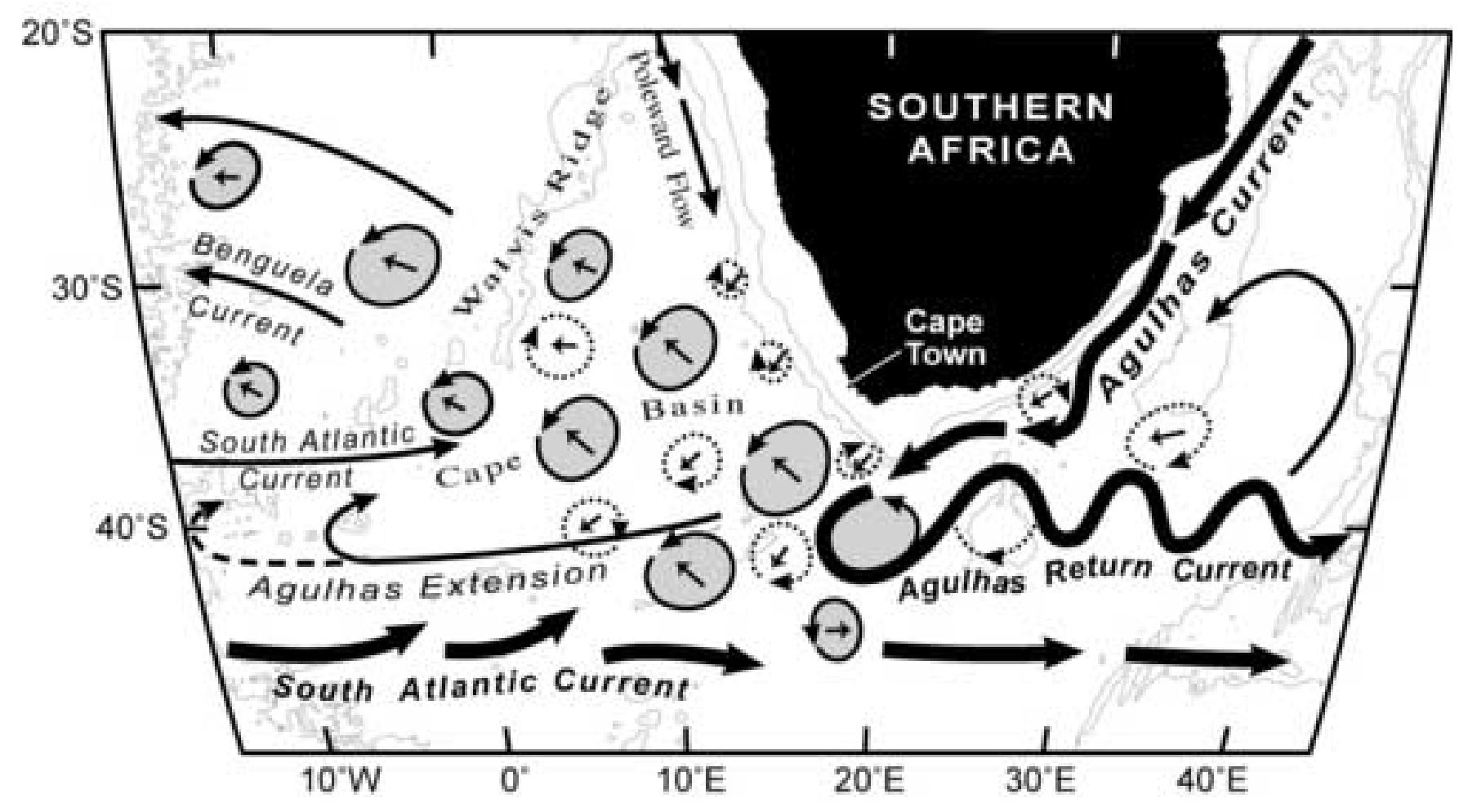




\section{Figure 2}

Click here to download high resolution image

\section{DRIFTER SPEEDS}

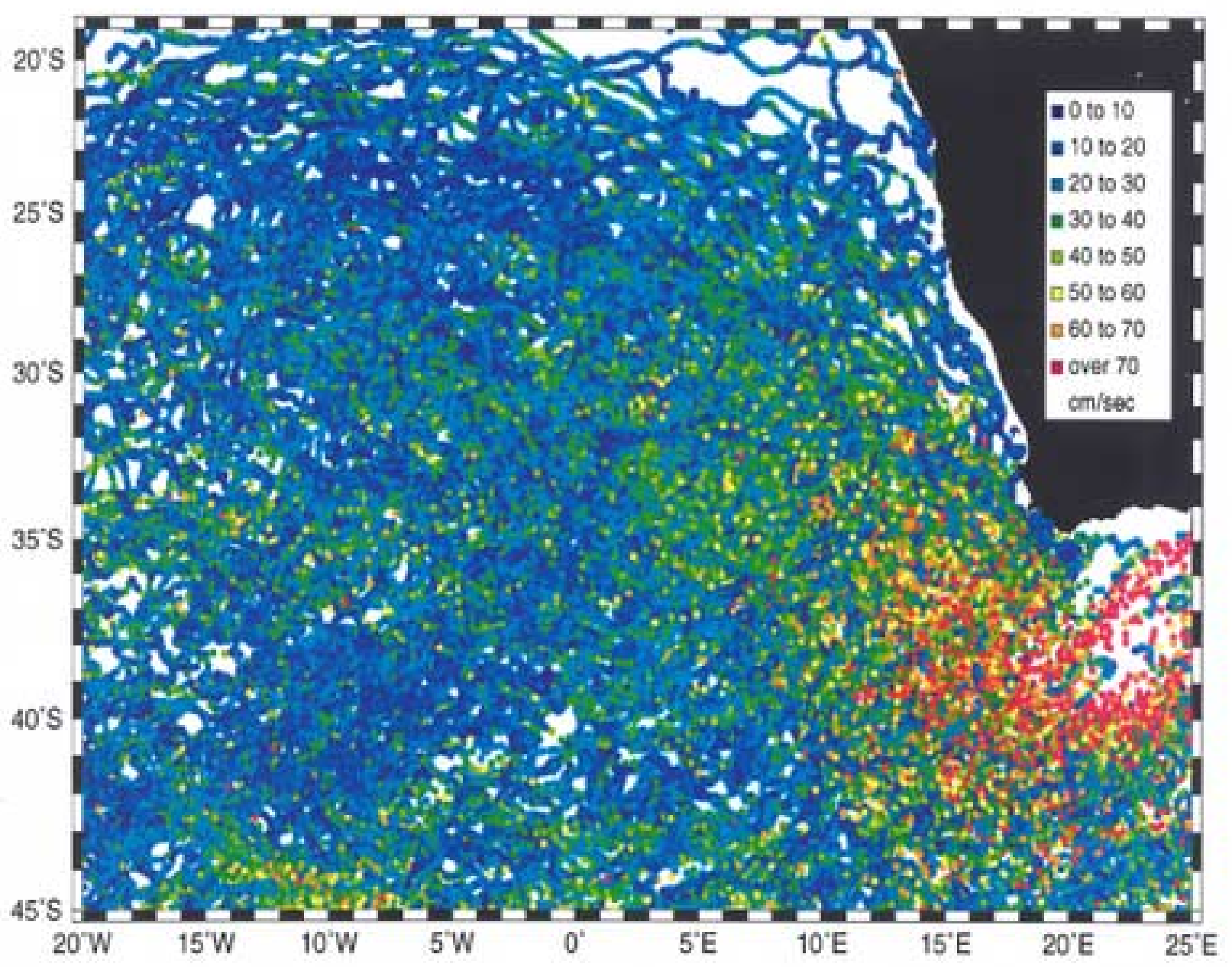




\section{Figure 3}

Click here to download high resolution image

FLOAT TRAJECTORIES

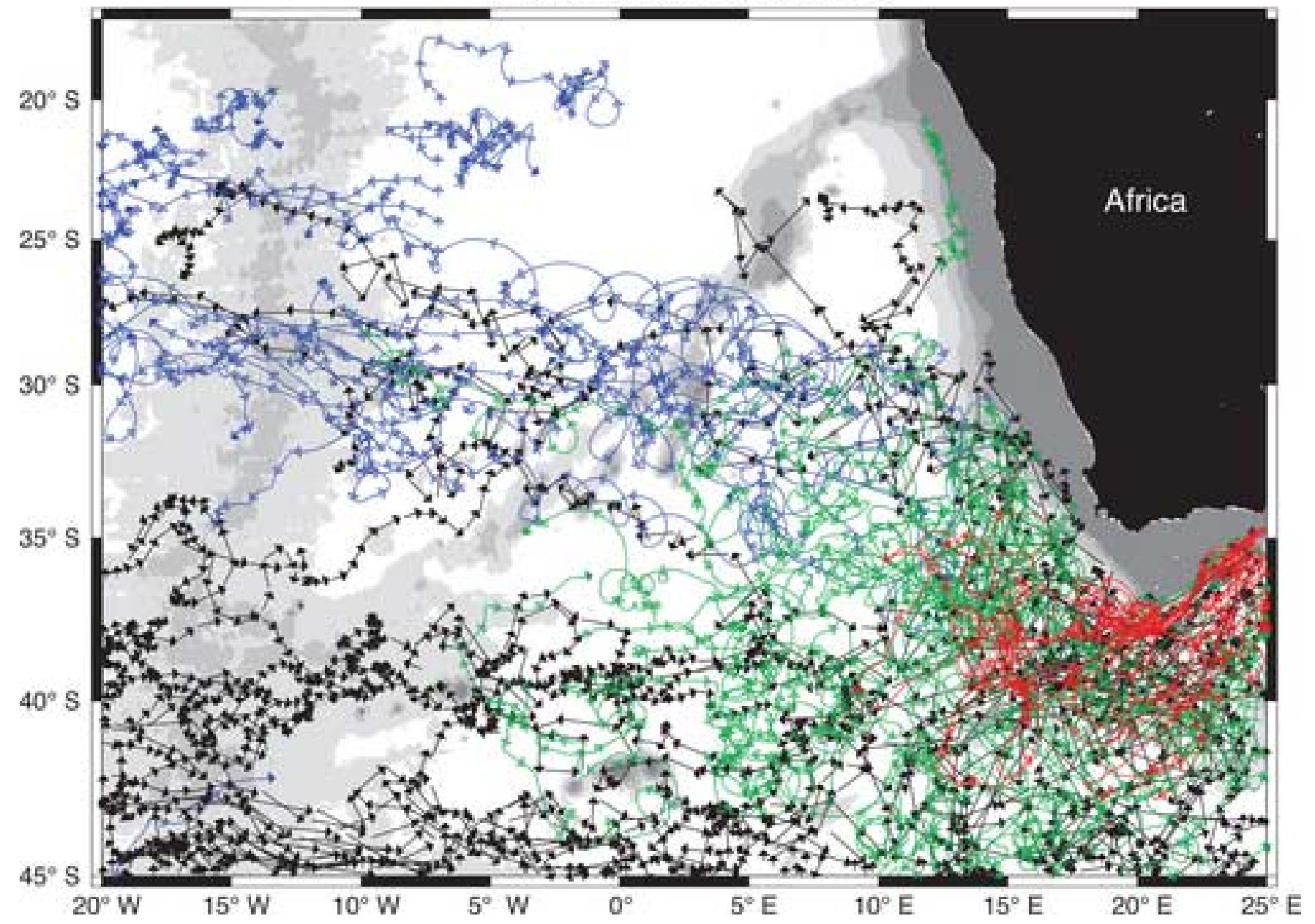


Click here to download high resolution image

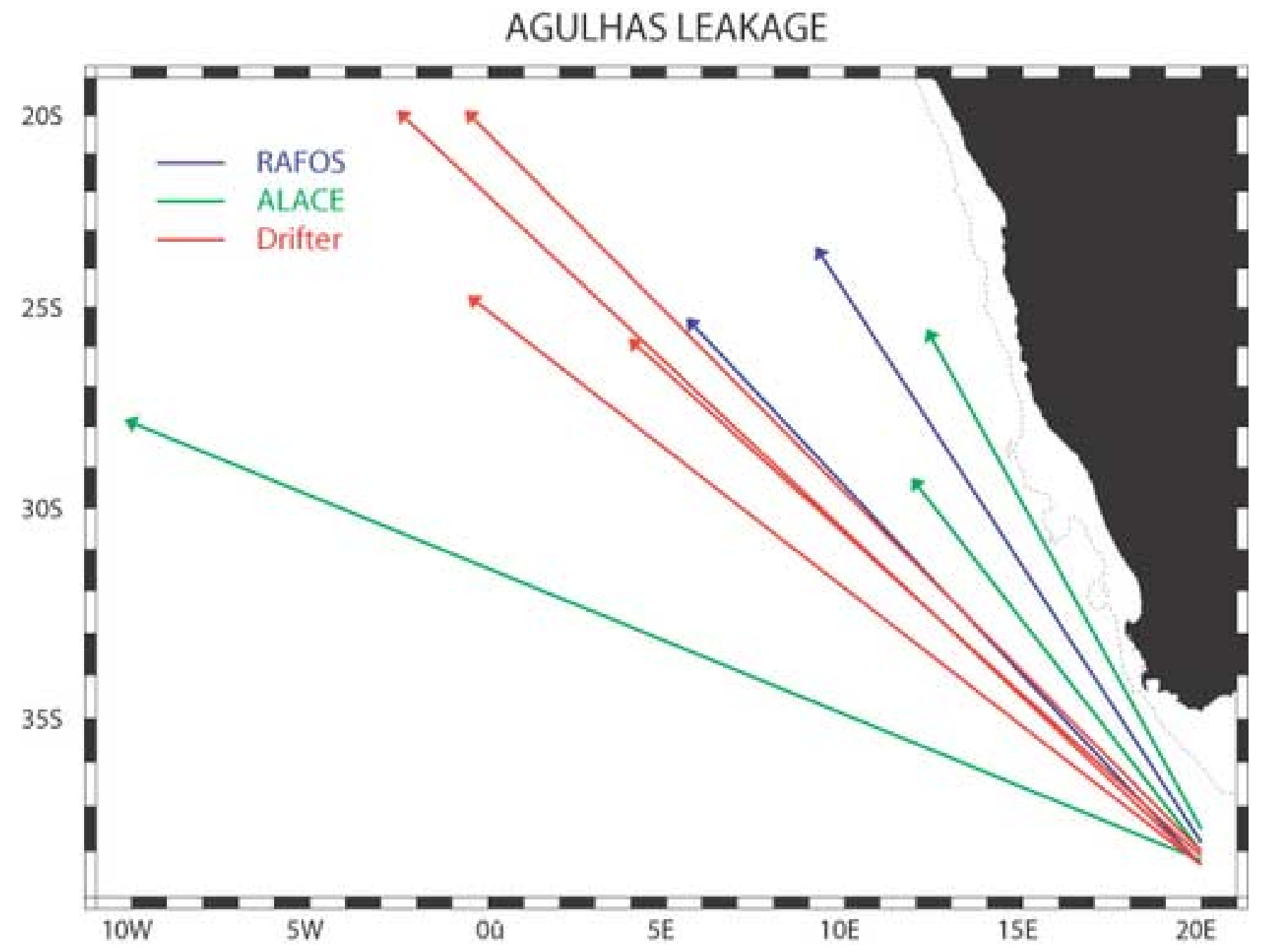


Click here to download high resolution image

\section{DRIFTERS LOOPING IN EDDIES}

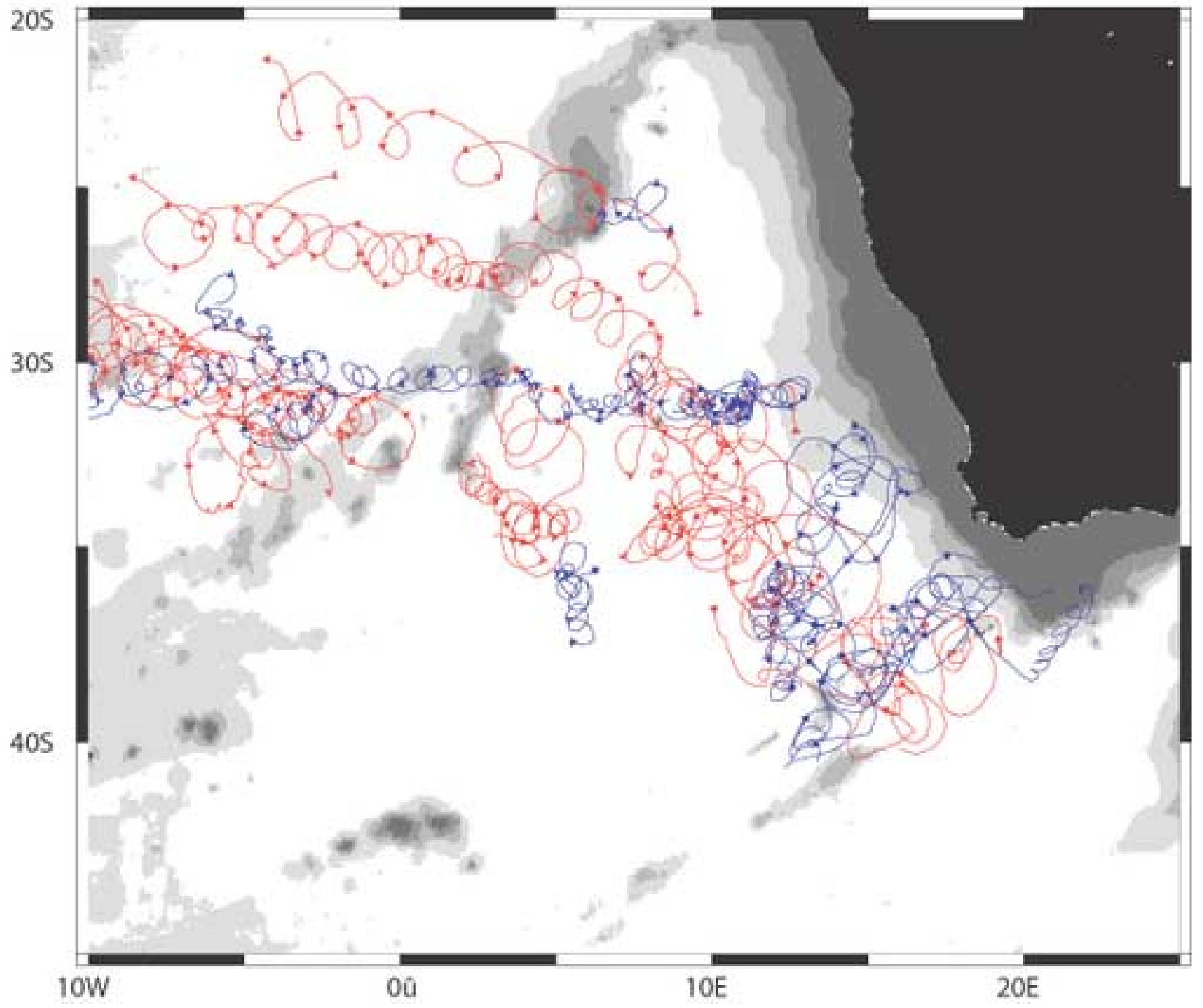


Figure 6

\section{FLOATS LOOPING IN EDDIES}

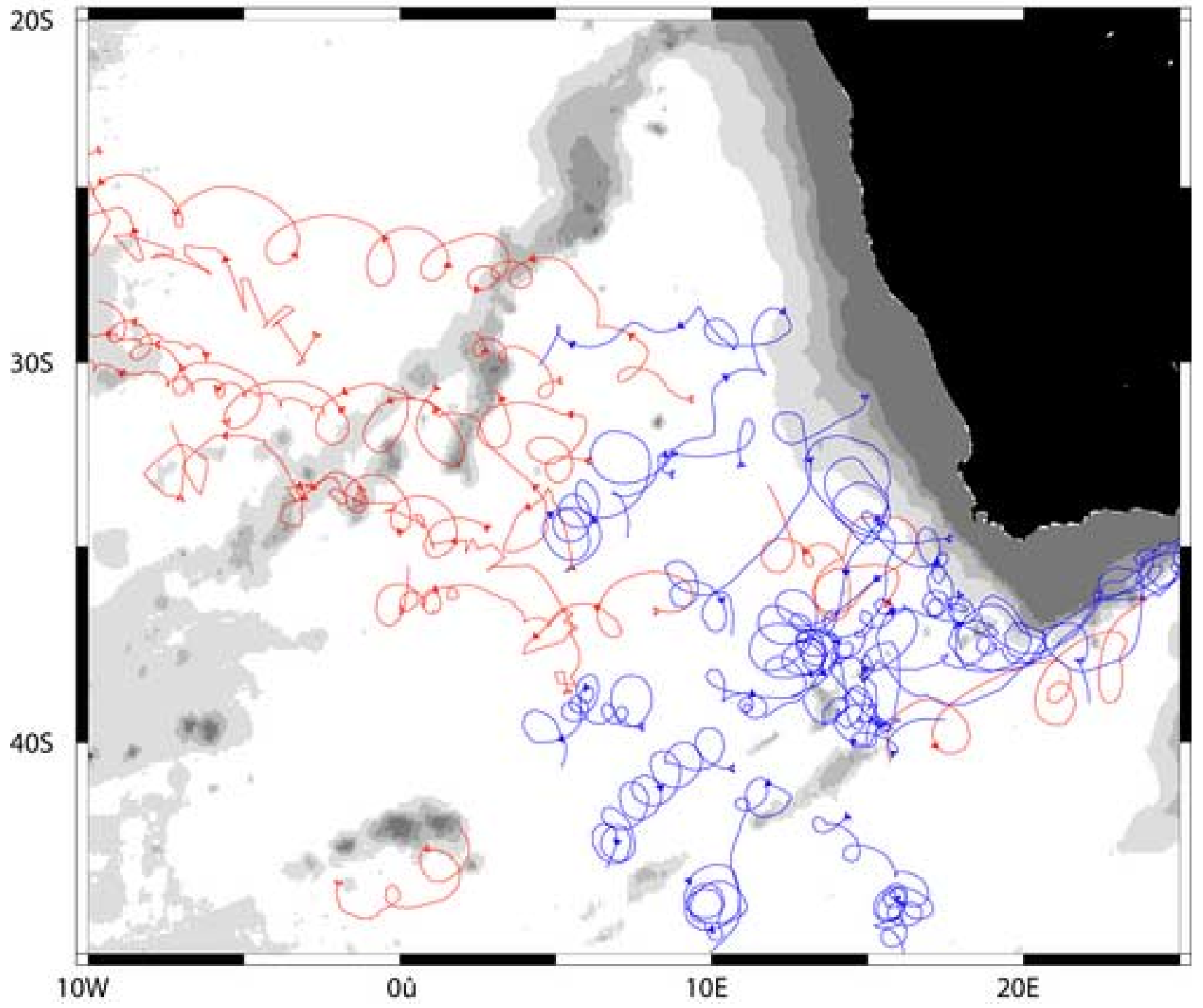


ANTICYCLONE TRAJECTORIES

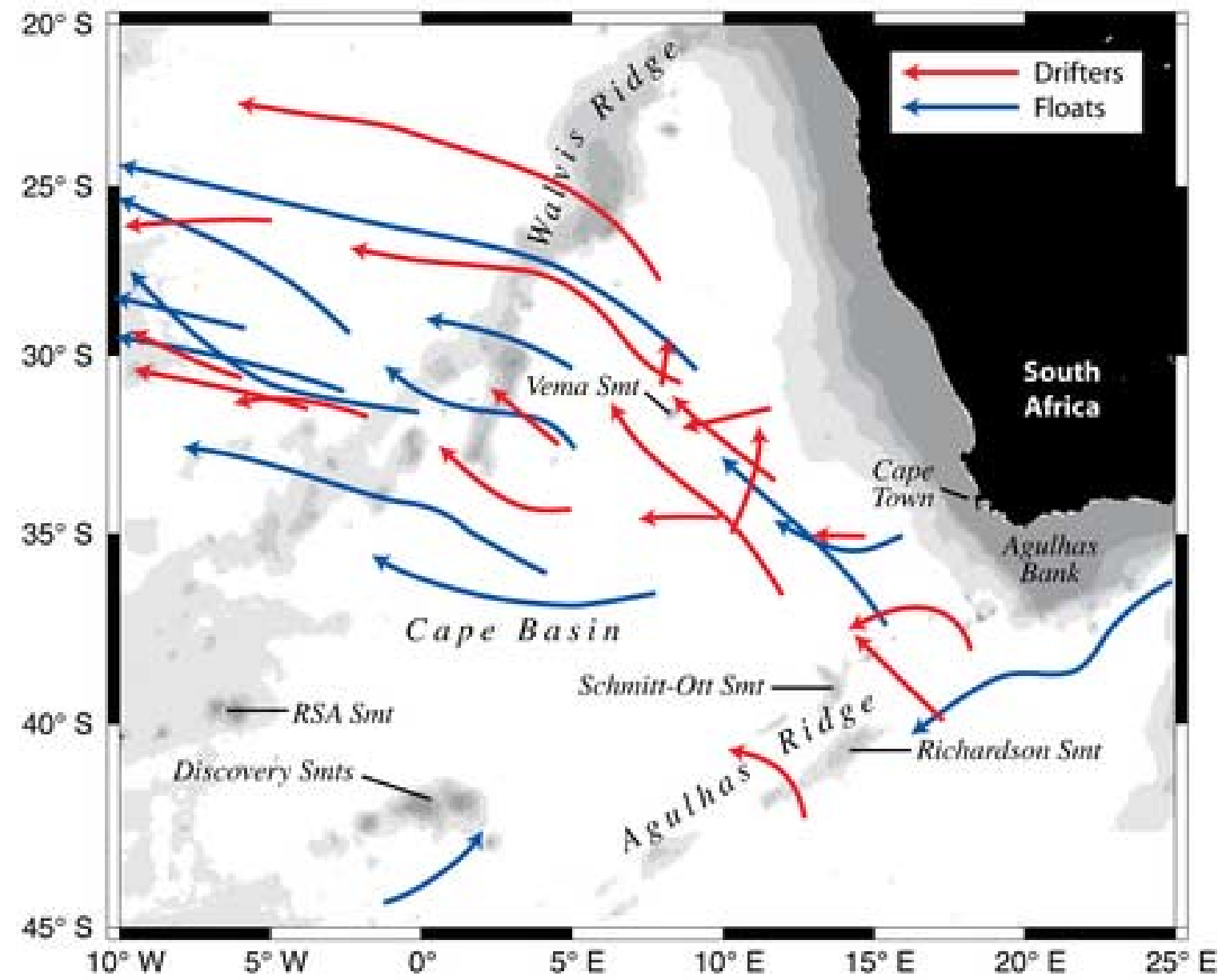


Click here to download high resolution image

CYCLONE TRAJECTORIES

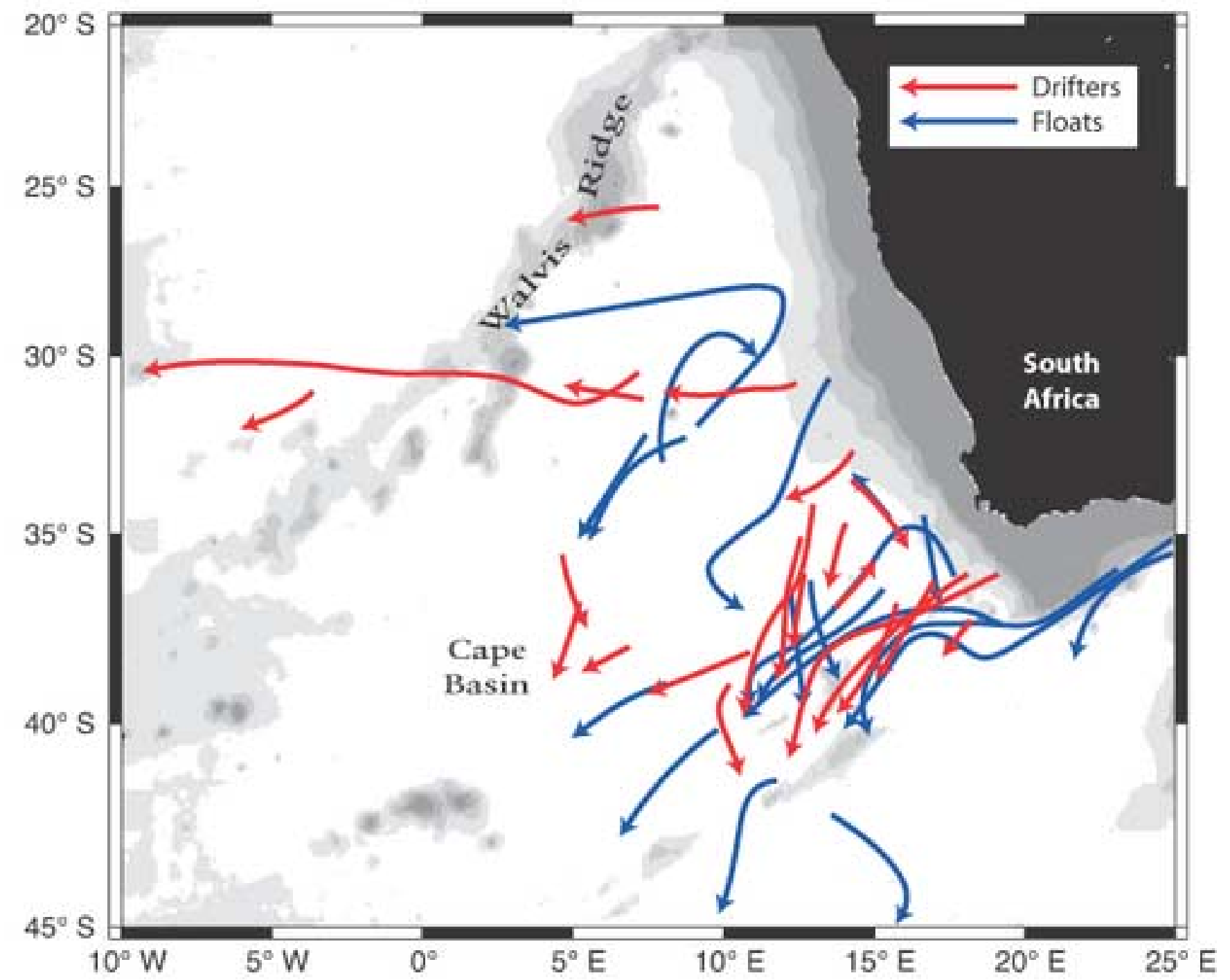


Click here to download high resolution image

\section{AGULHAS EXTENSION FLOATS}

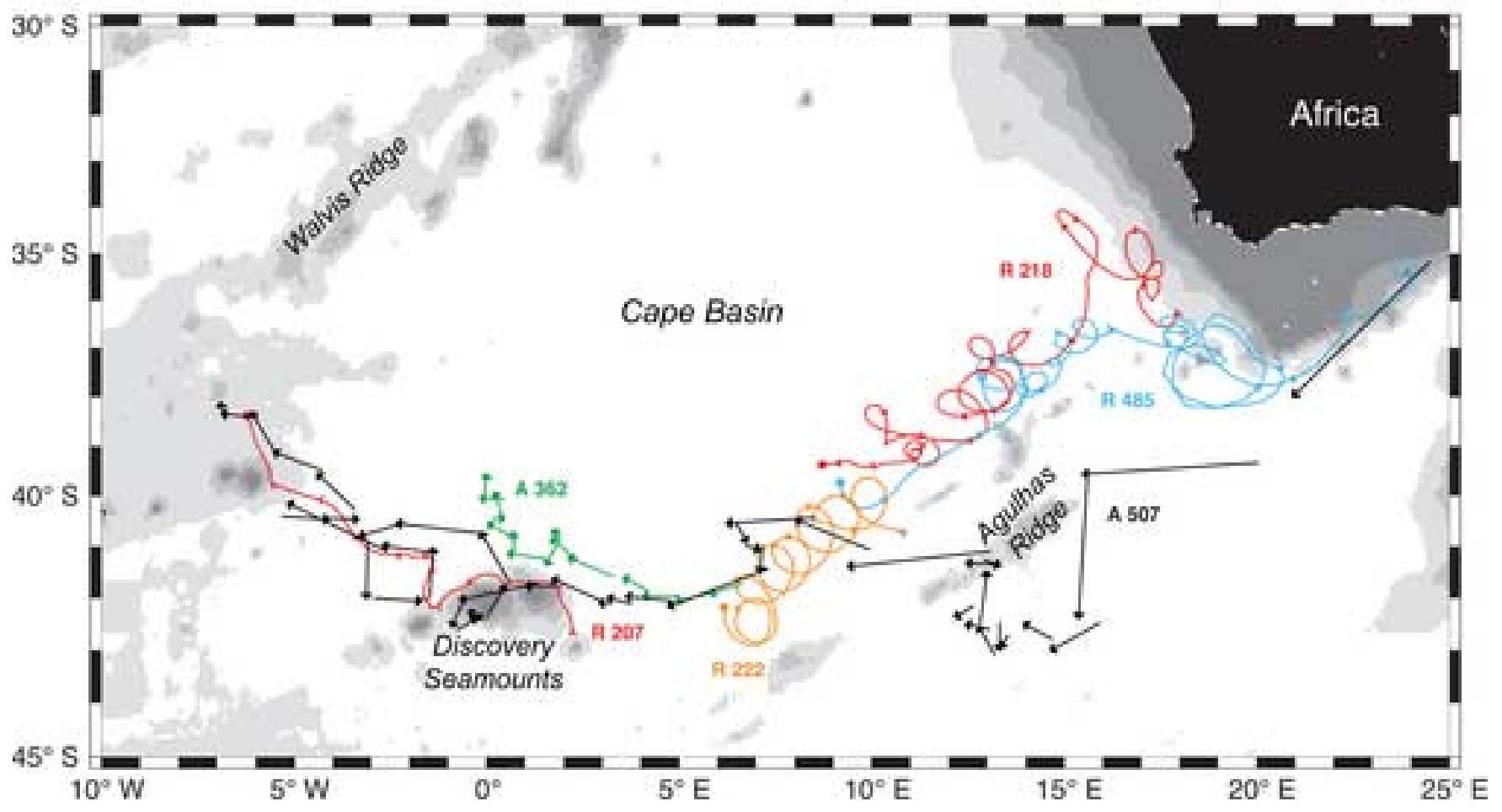


figure 10
Click here to download high resolution image

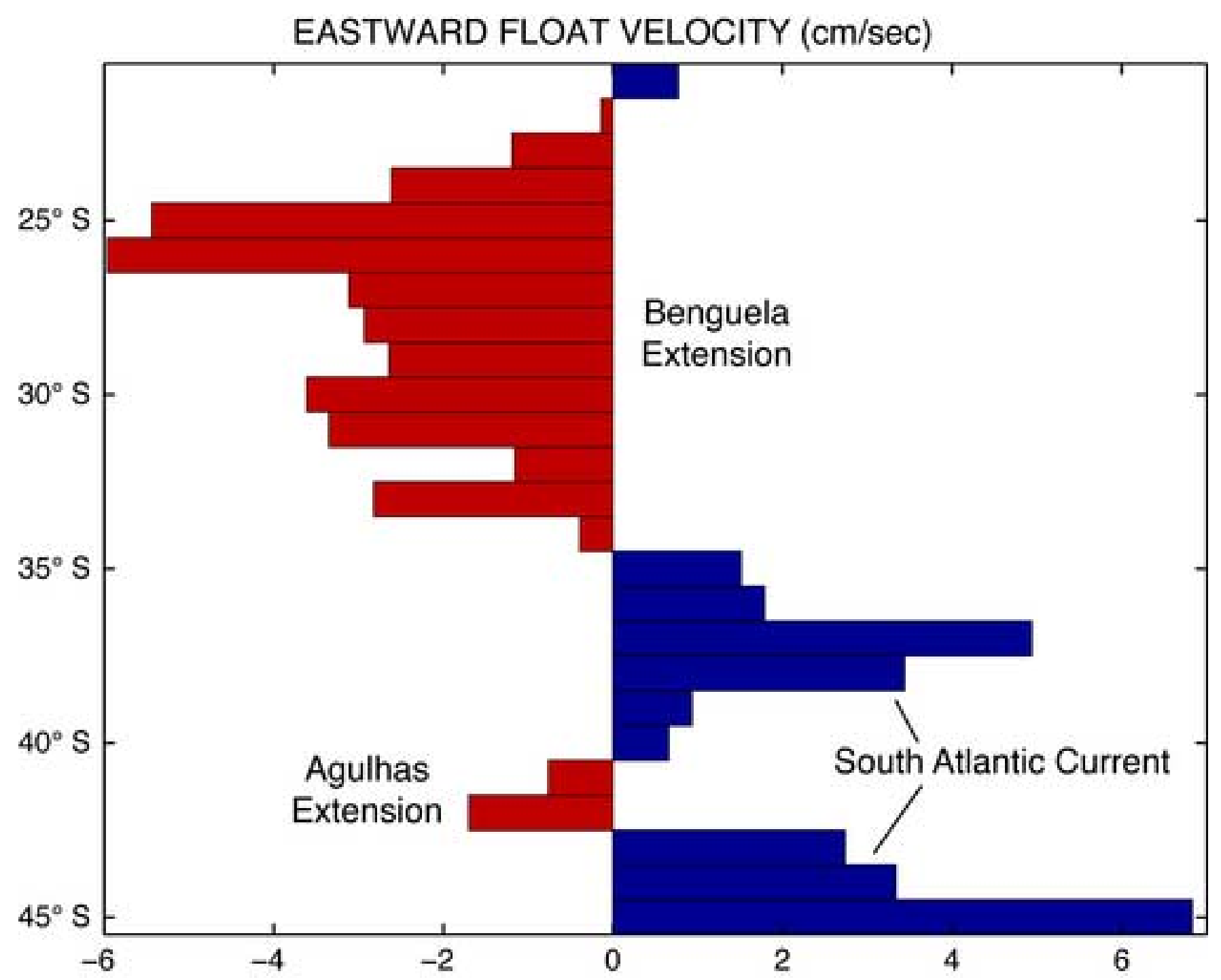




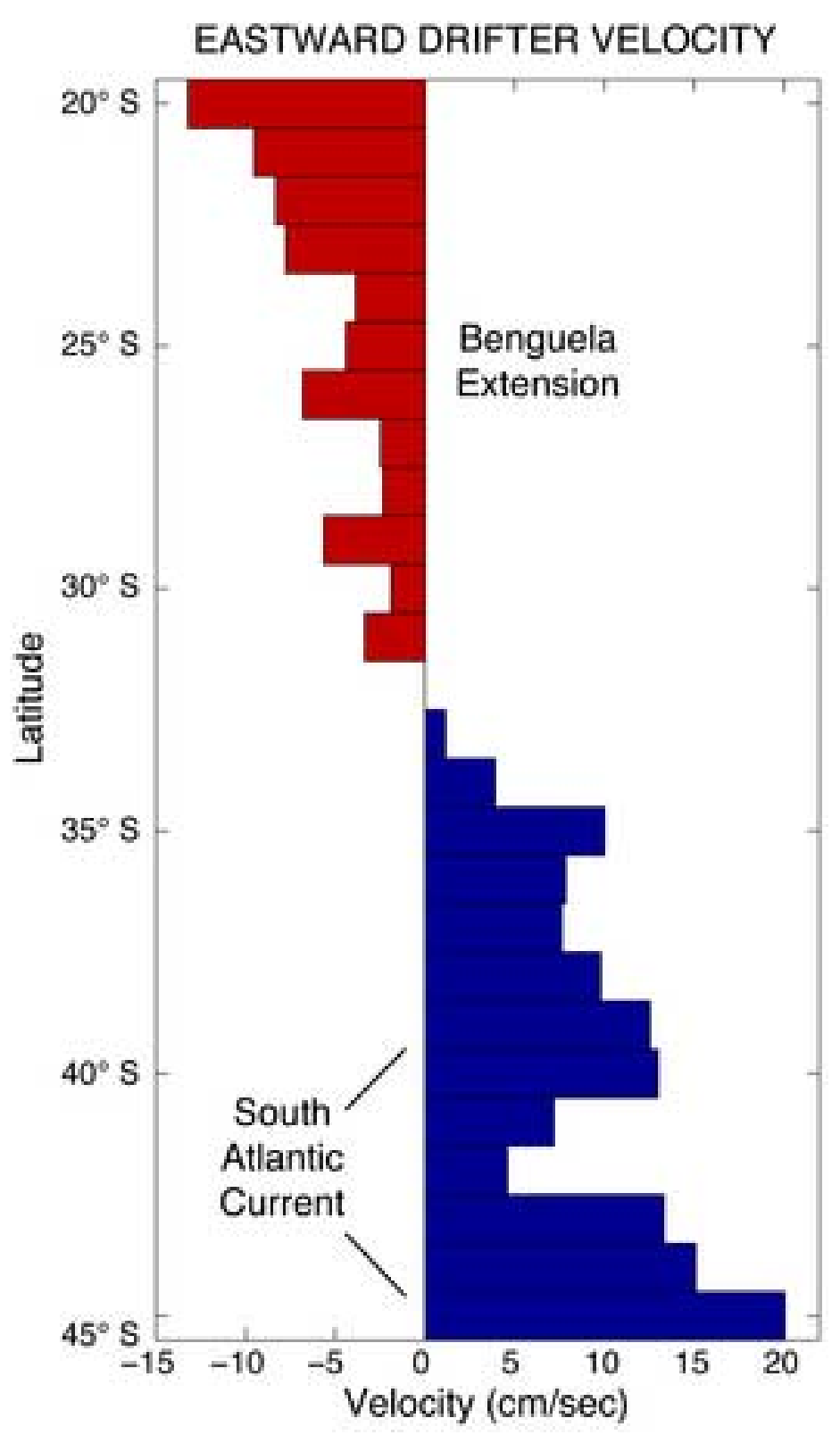

\section{EASTWARD GEOSTROPHIC VELOCITY}

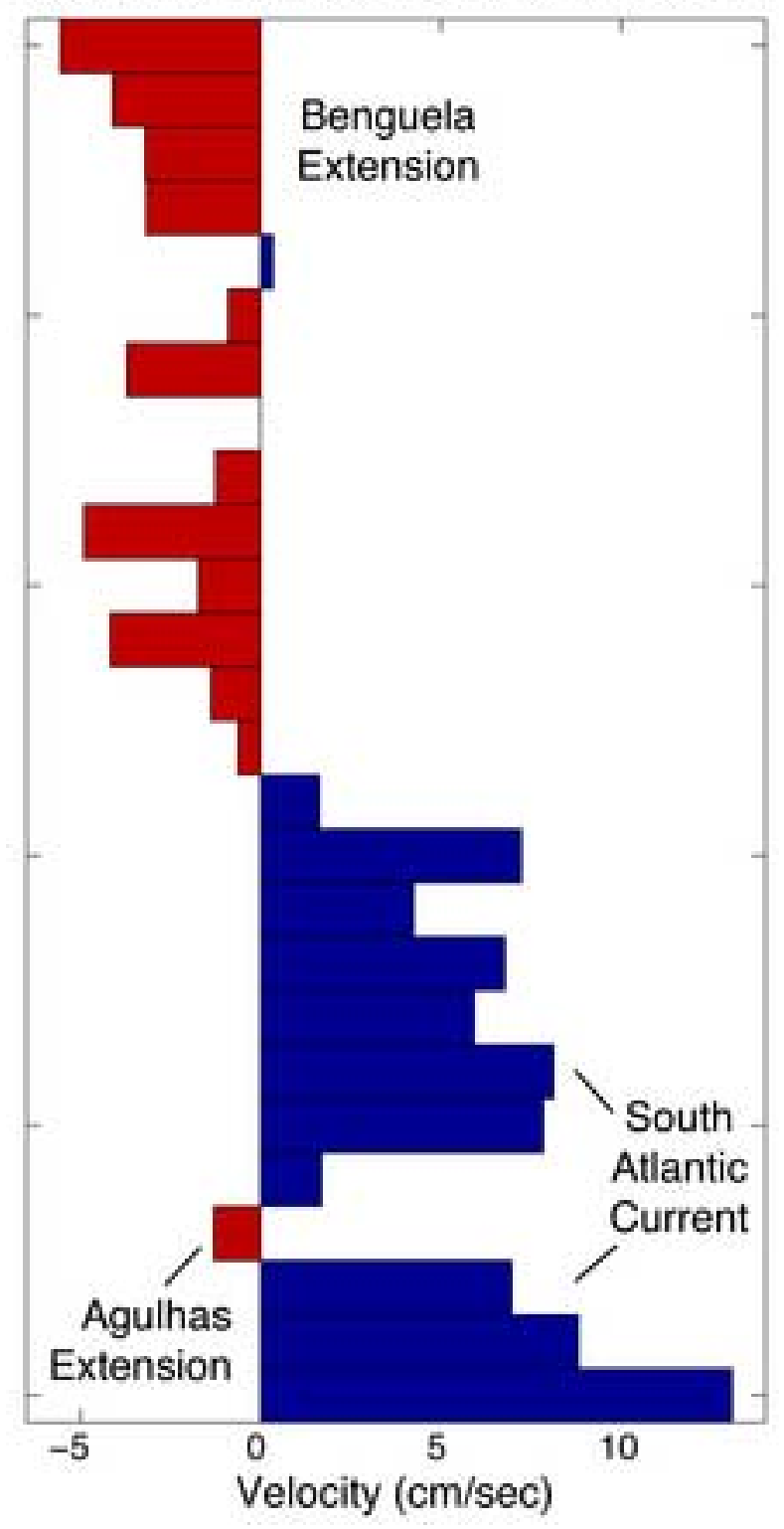


1

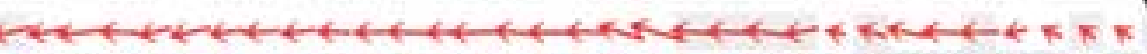

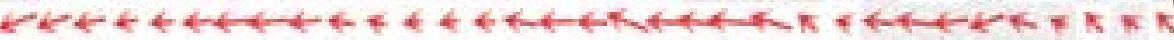

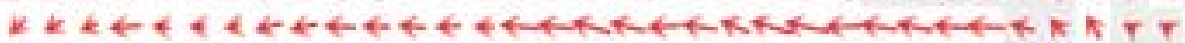

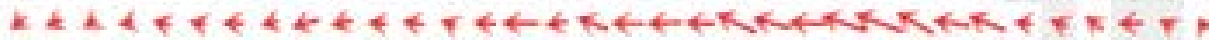

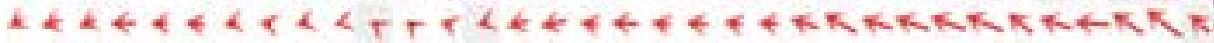

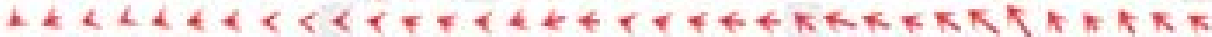

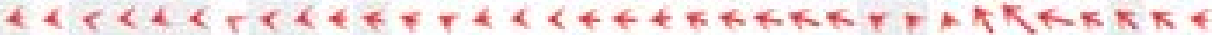

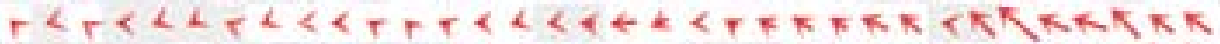

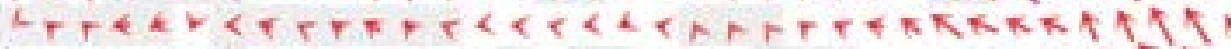

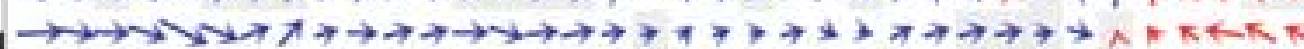

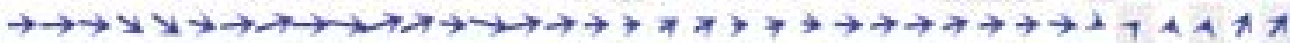
$\rightarrow \rightarrow \rightarrow \rightarrow \rightarrow \rightarrow \lambda \rightarrow \rightarrow \rightarrow \lambda \rightarrow \rightarrow \rightarrow \rightarrow \rightarrow \rightarrow \rightarrow \rightarrow \rightarrow \rightarrow \rightarrow \rightarrow \rightarrow>\rightarrow \rightarrow \rightarrow \lambda \rightarrow \lambda$

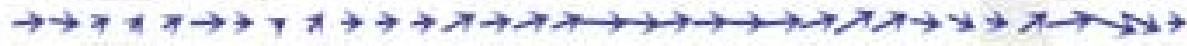

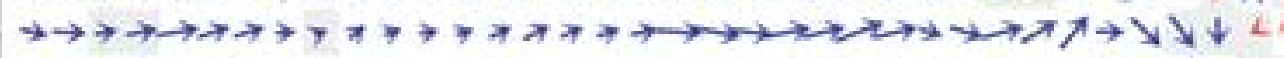


FLOAT VELOCITY VECTORS 


\section{Figure 14}

Click here to download high resolution image

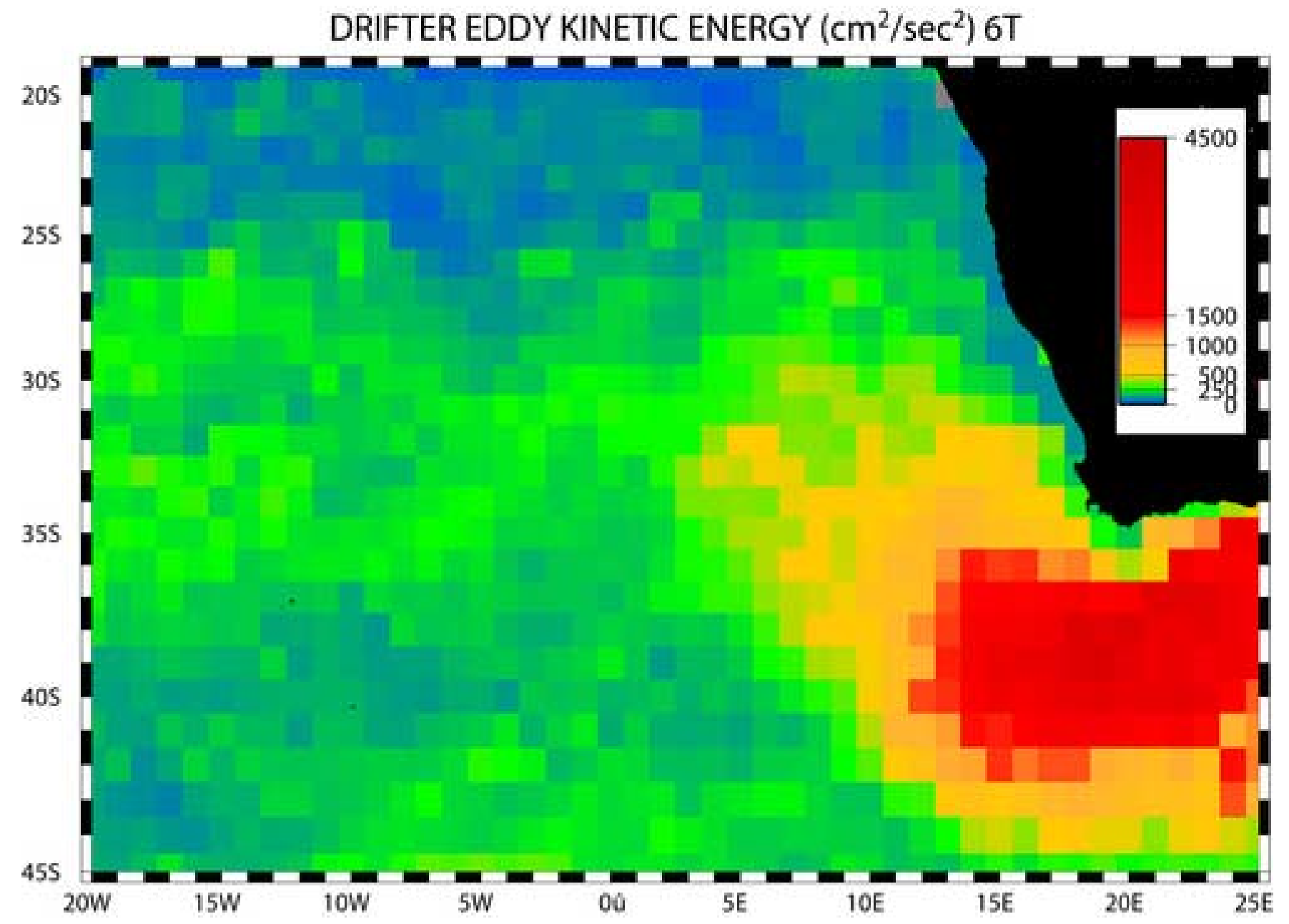


Click here to download high resolution image

FLOAT EDDY KINETIC ENERGY $\left(\mathrm{cm}^{2} / \mathrm{sec}^{2}\right)$

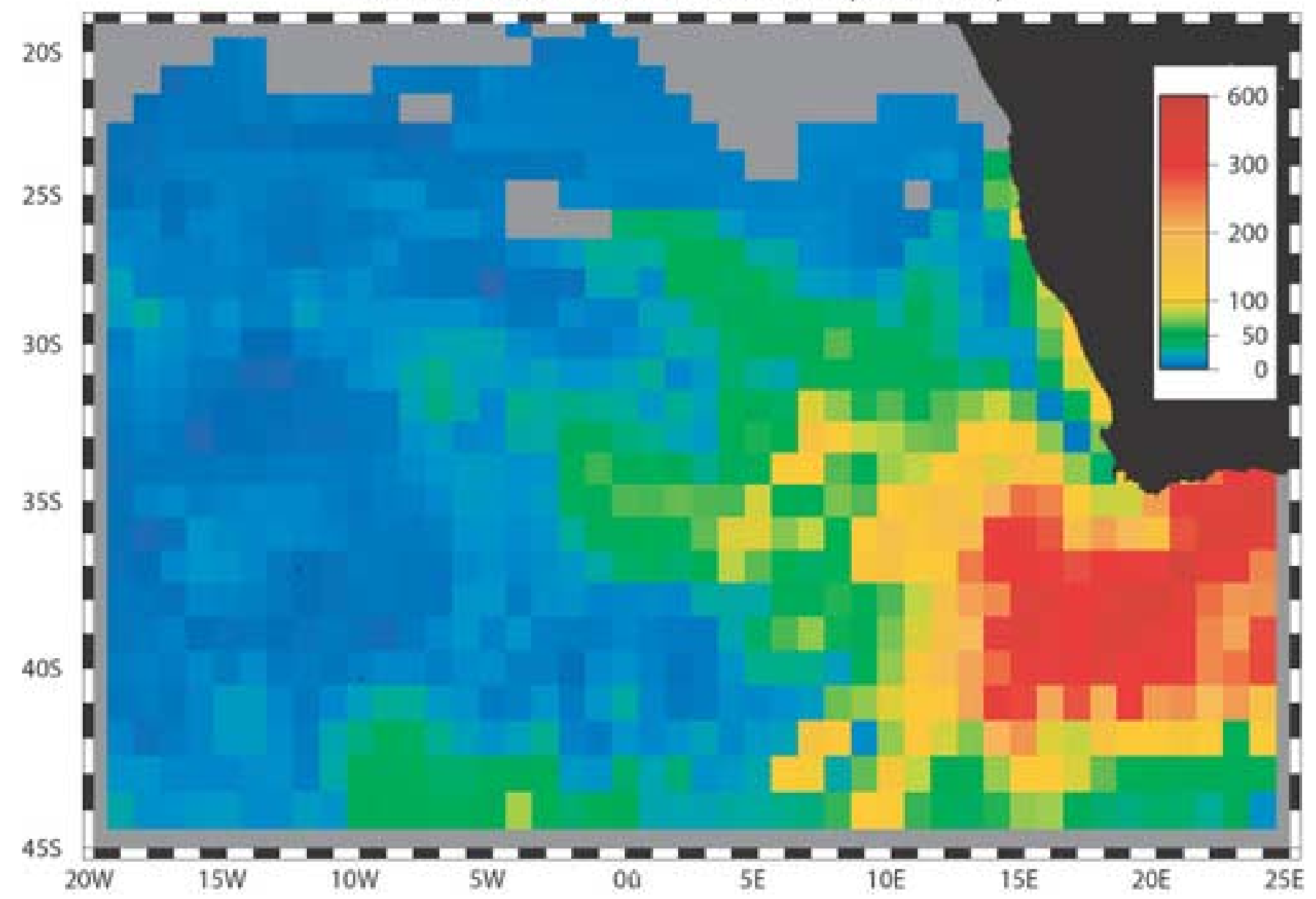

